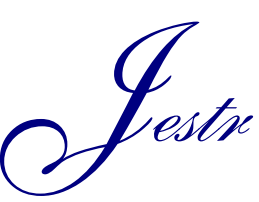

Research Article

\title{
Analysis on the Applicability Domain of the Linear Models During Study of the Lateral Dynamic Behaviour of the Railway Vehicles
}

\author{
Mădălina Dumitriu \\ Department of Railway Vehicles, University Politehnica of Bucharest, 313 Splaiul Independenţei, 060042, Bucharest, Romania
}

Received 15 March 2017; Accepted 10 September 2017

\begin{abstract}
The use of the linear models for the study in the dynamic behaviour of the railway vehicles provides quality information regarding a series of basic phenomena of the vehicle dynamics. This paper intends to set forth the running conditions for which the linear models can be utilized during the simulations regarding the lateral dynamic behaviour of the railway vehicles. This action relies on analyses that compare the results of the numerical simulations developed on the linear model of the vehicle with the ones corresponding to the non-linear model, which considers various characteristics of the track in correlation with the velocity regime. A good analogy is emphasized between the compared units, namely the lateral accelerations calculated in three reference points - at the carbody centre and above the bogies.
\end{abstract}

Keywords: railway vehicles, lateral dynamic behaviour, linear model, non-linear model, track lateral irregularities, lateral accelerations

\section{Introduction}

The study of the dynamic behaviour of the railway vehicles involves the use - as an investigation tool - of the numerical simulation codes developed on theoretical models of the vehicle and of the vehicle/track interaction [1,2]. The numerical simulations are useful tools to estimate the dynamic behaviour of the railway, in terms of the running stability [3 - 6], safety, ride quality and ride comfort, track fatigue $[7,8]$, and to optimize its dynamic performance [9, $10]$. It is evident that the models associated with such studies call for a high degree of reliability and trustworthiness, as a series of important factors affecting the dynamic behaviour of the railway vehicle should be taken into account [11]. Moreover, in the present context, when the issue of ,virtual homologation' arises, its model should be an accurate representation of all the aspects having an impact upon the dynamic behaviour of the real vehicle [11 - 13].

The complexity degree of the models used in the numerical simulations is generally determined as a function of the precision required from the results. The more complex the model, the closer to the reality the results, but it will be more difficult to derive some general conclusions regarding the basic phenomena of the vehicle dynamics. Quality and even quantity information can be obtained from less complex models.

The precision of the models for the study of the lateral dynamic behaviour of the railway vehicle depends a great deal on the modelling of the vehicle-track interaction conditions [14], which proves difficult due to the nonlinearity of the wheel-rail contact - of a geometric, elastic (the normal issue of the contact) and tribological (the tangential issue of the contact) nature.

\footnotetext{
"E-mail address:madalinadumitrii@yahoo.com

ISSN: 1791-2377@ 2017 Eastern Macedonia and Thrace Institute of Technology. All rights reserved. doi:10.25103/jestr.104.19
}

The paper deals with the non-linearity of a tribological nature of the wheel-rail contact and, related to it, the issue of the model that needs to be adopted for the calculation of the wheel-rail creep forces. Reaching numerical results of a high accuracy regarding the stability or the dynamic performance of the vehicle implies the selection of non-linear models [15 - 17] that often require long simulation times. For this reason, when selecting the model to calculate the creep forces, a reasonable compromise is turned to, between the accuracy of the results and the duration of the numerical simulations. An effective solution is Shen's non-linear model [18] or Polach's [19].

Despite of the above, there are still issues that can be studied by a linear model of the wheel-rail contact, based on which quality conclusions can be made in terms of the dynamic behaviour of the vehicle under various aspects [9, 20 - 22]. For instance, a first quality evaluation of the vehicle stability can be conducted via the linear model. Thus, the stability of the vehicle balance position can be defined, based on the analysis of natural values in the matrix of the system of movement linear equations [20]. A series of basic properties of the stable regime of the forced lateral vibrations is still based on the linear model. Moreover, it is possible to have a set of analyses related to the influence of the velocity or the suspension parameters upon the level of vibrations in the vehicle [21].

The interest for using the linear model of the wheel-rail contact is linked to the advantages thus derived. It is about simplifications in designing the applications for the numerical simulation of the dynamic behaviour of the vehicle and significantly lower calculation times, compared to the ones in the applications based on a non-linear model of the wheel-rail contact. On the other hand, the results coming from the linear model are a reference for the verification of the non-linear model.

As a result from the above facts, is it interesting to determine the applicability limits of the linear model in the study of the lateral dynamic behaviour of the railway 
vehicles. This issue comes naturally, as a consequence of the fact that the applicability domain of the linear model has to comply with meeting certain basic requirements associated with the presumption that the vehicle has a stable running. What this represents is that the wheelsets perform small oscillations with respect to the track axis, without the clearance consumption on the track and the velocity is smaller than the critical speed. On the other hand, the linear model in this paper to calculate the wheel-rail contact forces is based on Kalker theory [23], which means to verify the condition that the creepage in the wheel-rail contact points be sufficiently low $(1-1.5 \%)$.

This paper intends to establish the limits of the applicability domain of the linear models in the study of the lateral dynamic behaviour of the railway vehicles, carried out on the basis of the numerical simulations. The vehicle is represented by a complex model, with 21 degrees of freedom, which allows the study of the vehicle dynamics while running on a track with lateral irregularities. To calculate the wheel-rail creep forces, Polach's non-linear model is applied first [19] that is herein extended by introducing the influence of the load transfer between the wheels of the same wheelset upon the creep coefficients. What is obtained is a non-linear model of the vehicle, with non-linearity sources in the wheel-rail creep forces, the lateral reaction of the rail acting on the wheelset when its clearance on the track is consumed and the load transfer between the wheels of each wheelset. Afterwards, the wheelrail creep forces are calculated according to Kalker's linear theory [23] and the vehicle movement equations become linear, thus obtaining a linear model of the vehicle. More analyses based on these two models will be carried out, while considering various running conditions - running on a track with lateral irregularities of a harmonic, random shape or some that correspond to defects of an isolated type, in correlation with the speed regime. In this context, the applicability limits of the linear model will be determined, followed by comparison of the accelerations in three carbody reference points using the two models.

\section{The Model of the Vehicle}

To study the dynamic behaviour of the railway vehicle during running on a track with lateral irregularities, the model in Fig. 1 and Fig. 2 [24, 25] will be adopted, whose parameters are described in Annex 1.

The vehicle carbody is represented with a rigid body with the following motions: lateral $y_{c}$, roll $\mathrm{j}_{c}$ and yaw $\mathrm{a}_{c}$. The bogie chassis is modelled as a three-degree freedom rigid body: lateral $y_{b i}$, roll $\mathrm{j}_{b i}$ and yaw $\mathrm{a}_{b i}$, with $i=1$ or 2 . The wheelsets can perform the following independent movements: a lateral translation $y_{w j,(j+1)}$ and a motion of rotation around the vertical wheelset - yaw, $\mathrm{a}_{w j, j+1}$, where $j=$ $2 i-1$, with $i=1$ or 2 ; the bogie $i$ has the wheelsets $j$ and $j+$ 1. Also, the wheelset has a rotation around its own axis at the angular speed $\mathrm{W}_{w j,(j+1)}=V / r_{w}+\mathrm{w}_{w j, j+1}$, where $\mathrm{w}_{w j, j+1}$ is the angular sliding speed of the wheelset compared to $V / r_{w}$, and $V$ is the vehicle velocity. Likewise, the wheelset makes two more motions, namely rolling and bouncing, which are not independent but they affect the wheelset lateral motion on the track.

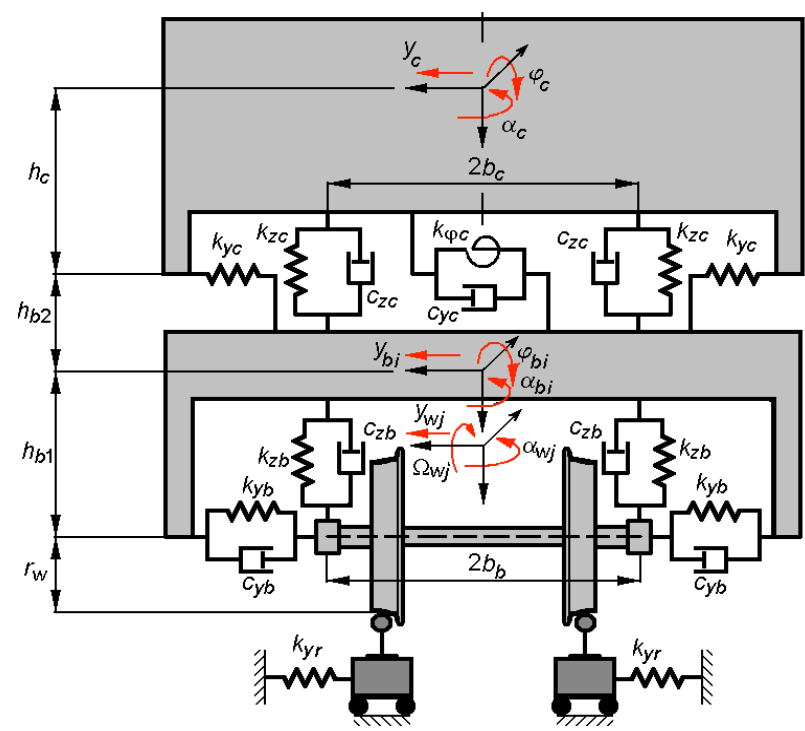

Fig. 1. Vehicle model - front view.

\section{The Non-Linear Movement Equations of the Vehicle}

The equations of the motions of the vehicle carbody are:

$$
\begin{aligned}
& m_{c} \ddot{y}_{c}+c_{y c}\left[2\left(\dot{y}_{c}+h_{c} \dot{\phi}_{c}\right)-\left(\dot{y}_{b 1}+\dot{y}_{b 2}\right)+h_{b 2}\left(\dot{\phi}_{b 1}+\dot{\phi}_{b 2}\right)\right]+ \\
& +2 k_{y c}\left[2\left(y_{c}+h_{c} \phi_{c}\right)-\left(y_{b 1}+y_{b 2}\right)+h_{b 2}\left(\phi_{b 1}+\phi_{b 2}\right)\right]=0 ; \\
& J_{x c} \ddot{\phi}_{c}+2 c_{z c} b_{c}^{2}\left[2 \dot{\phi}_{c}-\left(\dot{\phi}_{b 1}+\dot{\phi}_{b 2}\right)\right]+ \\
& +c_{y c} h_{c}\left[2\left(\dot{y}_{c}+h_{c} \dot{\phi}_{c}\right)-\left(\dot{y}_{b 1}+\dot{y}_{b 2}\right)+h_{b 2}\left(\dot{\phi}_{b 1}+\dot{\phi}_{b 2}\right)\right]+ \\
& +\left(k_{\phi c}+2 k_{z c} b_{c}^{2}\right)\left[2 \phi_{c}-\left(\phi_{b 1}+\phi_{b 2}\right)\right]+ \\
& +2 k_{y c} h_{c}\left[2\left(y_{c}+h_{c} \phi_{c}\right)-\left(y_{b 1}+y_{b 2}\right)+h_{b 2}\left(\phi_{b 1}+\phi_{b 2}\right)\right]- \\
& -m_{c} g h_{c} \phi_{c}=0 ; \\
& J_{z c} \ddot{\alpha}_{c}+2 c_{x c} b_{c}^{2}\left[2 \dot{\alpha}_{c}-\left(\dot{\alpha}_{b 1}+\dot{\alpha}_{b 2}\right)\right]+ \\
& +c_{y c} a_{c}\left[2 a_{c} \dot{\alpha}_{c}-\left(\dot{y}_{b 1}-\dot{y}_{b 2}\right)+h_{b 2}\left(\dot{\phi}_{b 1}-\dot{\phi}_{b 2}\right)\right]+ \\
& +2 k_{x c} b_{c}^{2}\left[2 \alpha_{c}-\left(\alpha_{b 1}+\alpha_{b 2}\right)\right]+ \\
& +2 k_{y c} a_{c}\left[2 a_{c} \alpha_{c}-\left(y_{b 1}-y_{b 2}\right)+h_{b 2}\left(\phi_{b 1}-\phi_{b 2}\right)\right]=0 .
\end{aligned}
$$

The equations of motion for the bogie $i$, for $i=1,2$ and $j$ $=2 \mathrm{i}-1$, are:

$$
\begin{aligned}
& m_{b} \ddot{y}_{b i}+c_{y c}\left(\dot{y}_{b i}-h_{b 2} \dot{\phi}_{b i}-\dot{y}_{c}-h_{c} \dot{\phi}_{c} \mp a_{c} \dot{\alpha}_{c}\right)+ \\
& +2 c_{y b}\left[2\left(\dot{y}_{b i}+h_{b 1} \dot{\phi}_{b i}\right)-\left(\dot{y}_{w j}+\dot{y}_{w(j+1)}\right)\right]+ \\
& +2 k_{y c}\left(y_{b i}-h_{b 2} \phi_{b i}-y_{c}-h_{c} \phi_{c} \mp a_{c} \alpha_{c}\right)+ \\
& +2 k_{y b}\left[2\left(y_{b i}+h_{b 1} \phi_{b i}\right)-\left(y_{w j}+y_{w(j+1)}\right)\right]=0 ; \\
& J_{x b} \ddot{\phi}_{b i}+2 c_{z c} b_{c}^{2}\left(\dot{\phi}_{b i}-\dot{\phi}_{c}\right)+ \\
& +c_{y c} h_{b 2}\left(h_{b 2} \dot{\phi}_{b i}-\dot{y}_{b i}+\dot{y}_{c}+h_{c} \dot{\phi}_{c} \pm a_{c} \dot{\alpha}_{c}\right)+ \\
& +2 c_{y b} h_{b 1}\left[2\left(h_{b 1} \dot{\phi}_{b i}+\dot{y}_{b i}\right)-\left(\dot{y}_{w j}+\dot{y}_{w(j+1)}\right)\right]+ \\
& +4 c_{z b} b_{b}^{2} \dot{\phi}_{b i}+\left(k_{\phi c}+2 k_{z c} b_{c}^{2}\right)\left(\phi_{b i}-\phi_{c}\right)+ \\
& 2 k_{y c} h_{b 2}\left(h_{b 2} \phi_{b i}-y_{b i}+y_{c}+h_{c} \phi_{c} \pm a_{c} \alpha_{c}\right)+ \\
& +2 k_{y b} h_{b 1}\left[2\left(h_{b 1} \phi_{b i}+y_{b i}\right)-\left(y_{w j}+y_{w(j+1)}\right)\right]+ \\
& +\left[4 k_{z b} b_{b}^{2}-g\left(h_{12} m_{c} / 2+h_{b 1} m_{b}\right)\right] \phi_{b i}=0 \\
& \text { with } h_{12}=h_{b 1}+h_{b 2} ;
\end{aligned}
$$




$$
\begin{aligned}
& J_{z b} \ddot{\alpha}_{b i}+2 c_{x c} b_{c}^{2}\left(\dot{\alpha}_{b i}-\dot{\alpha}_{c}\right)+ \\
& +2 c_{x b} b_{b}^{2}\left[2 \dot{\alpha}_{b i}-\left(\dot{\alpha}_{w j}+\dot{\alpha}_{w(j+1)}\right)\right]+ \\
& +2 c_{y b} a_{b}\left[2 a_{b} \dot{\alpha}_{b i}-\left(\dot{y}_{w j}-\dot{y}_{w(j+1)}\right)\right]+ \\
& +2 k_{x c} b_{c}^{2}\left(\alpha_{b i}-\alpha_{c}\right)+ \\
& +2 k_{x b} b_{b}^{2}\left[2 \alpha_{b i}-\left(\alpha_{w j}+\alpha_{w(j+1)}\right)\right]+ \\
& +2 k_{y b} a_{b}\left[2 a_{b} \alpha_{b i}-\left(y_{w j}-y_{w(j+1)}\right)\right]=0 .
\end{aligned}
$$

For the wheelsets $j$, respectively $j+1$, for $j=2 i-1$ and $i$ $=1,2$, the equations of lateral displacement and yaw motions and the equation of the rotation motion around the wheelset axis are:

$$
\begin{aligned}
& m_{w} \ddot{y}_{w j, j+1}+2 c_{y b}\left[\dot{y}_{w j, j+1}-\dot{y}_{b i}-h_{b 1} \dot{\phi}_{b i} \mp a_{b} \dot{\alpha}_{b i}\right]+ \\
& +2 k_{y b}\left[y_{w j, j+1}-y_{b i}-h_{b 1} \phi_{b i} \mp a_{b} \alpha_{b i}\right]+ \\
& =Y_{j,(j+1) 1}+Y_{j,(j+1) 2}-Y_{\sigma j, j+1}
\end{aligned}
$$

$$
\begin{aligned}
& J_{z w} \ddot{\alpha}_{w j, j+1}+2 c_{x b} b_{b}^{2}\left(\dot{\alpha}_{w j, j+1}-\dot{\alpha}_{b i}\right)+2 k_{x b} b_{b}^{2}\left(\alpha_{w j, j+1}-\alpha_{b i}\right)+ \\
& +J_{y w} \frac{V}{r_{w}} \dot{\phi}_{w j, j+1}=-e_{w}\left[X_{j,(j+1) 1}-X_{j,(j+1) 2}\right] . \\
& J_{y w} \dot{\omega}_{w j, j+1}=-r_{w}\left[X_{j,(j+1) 1}+X_{j,(j+1) 2}\right],
\end{aligned}
$$

where $e_{w}, r_{w}$ - the coordinates of the wheel-rail contact points when the wheelset is in a median position on the track; the term $J_{y w}\left(V / r_{w}\right) \dot{\phi}_{w j, j+1}$ corresponds to the gyroscopic moment due to the combined effect of the wheelset rotation motion around its own axis with the roll motion $\varphi_{w j, j+1}[26] ; X_{j,(j+1) 1,2}$ are the longitudinal forces and $Y_{j,(j+1) 1,2}$ - represent the guidance forces acting upon the wheelsets $j$ and $j+1$ respectively, in the wheel/rail contact points 1 or 2 .

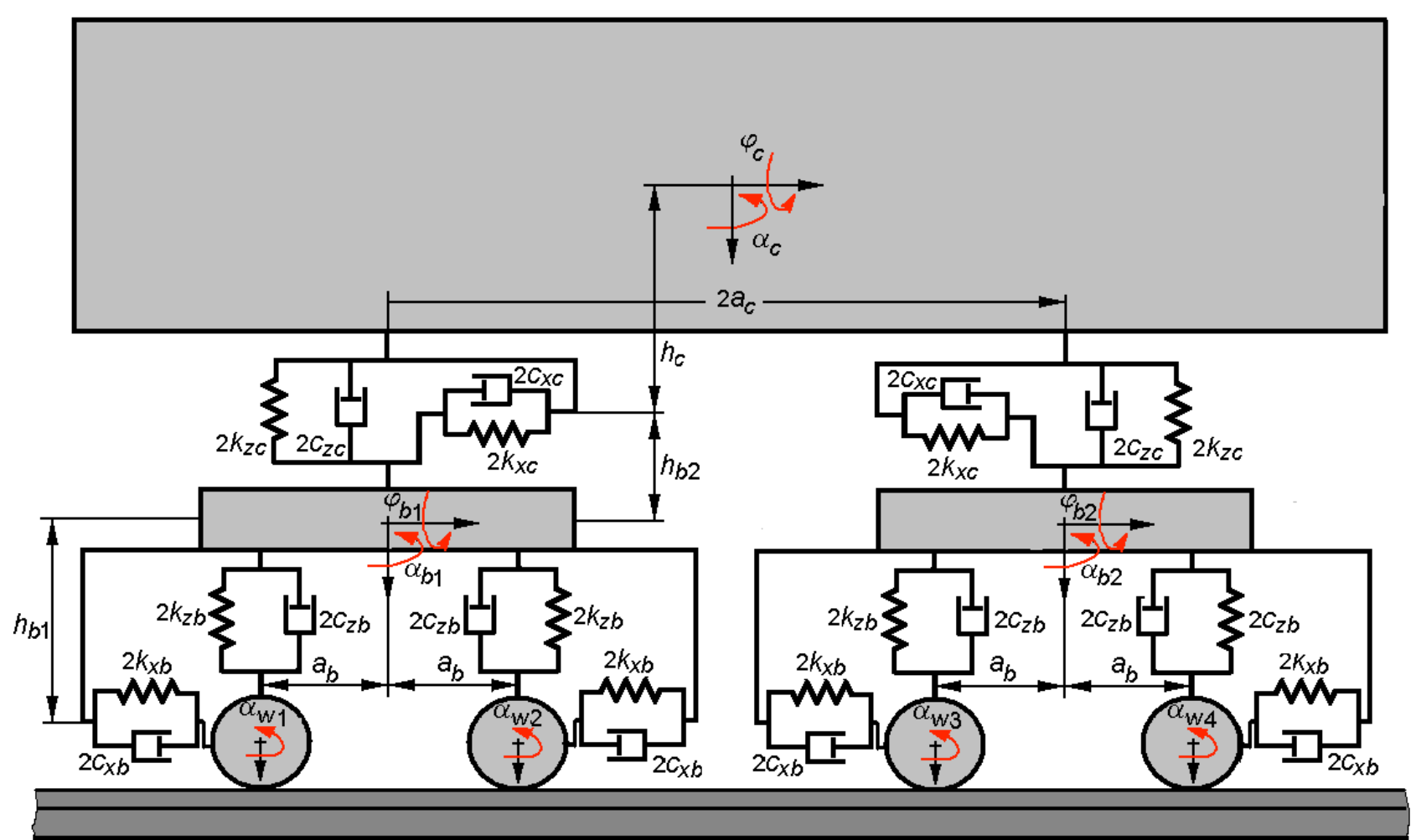

Fig. 2. Vehicle model - side view.

The motion equations $(1-9)$ can be solved by RungeKutta method.

The modelling of the situation where the wheelsets consume the clearance on the track $\mathrm{s}$ is achieved by the introduction of the lateral reaction with a non-linear characteristic $Y_{\sigma j,(j+1) 1,2}$, which acts upon the front wheel [27]. The equation of such force is as such

$$
\begin{aligned}
& Y_{\sigma j, j+1}=H\left(\left|y_{w j, j+1}-\zeta_{j, j+1}\right|-\frac{\sigma}{2}\right) \operatorname{sign}\left(y_{w j, j+1}-\zeta_{j, j+1}\right) \\
& * k_{y r}\left(\left|y_{w j, j+1}-\zeta_{j, j+1}\right|-\frac{\sigma}{2}\right)
\end{aligned}
$$

where $H($.$) is the Heaviside's unit step function, and function$ $\zeta_{j, j+1}$ describes the track irregularities against each wheelset.
The bouncing and roll equations of the wheelsets, motions that are dependent on the lateral displacement of the wheelset on the track. When considering that the bounce coming from the lateral displacement of the wheelset on the track is very low [26], the inertia effect of the wheelset mass in the vertical direction can be thus neglected. Hence, the balance equation of the vertical forces can be written as

$Q_{j,(j+1) 1}+Q_{j,(j+1) 2}=2 Q_{w}$

where $Q_{j,(j+1) 1,2}$ are the vertical loads in the wheel/rail contact points and $Q_{w}$ is the static load on the wheel.

The equation of the wheelset roll motion is 


$$
\begin{aligned}
& J_{x w} \ddot{\phi}_{w j, j+1}-J_{y w} \frac{V}{r_{w}} \dot{\alpha}_{w j, j+1}-2 b_{b}^{2} c_{z b} \dot{\phi}_{b i}-2 b_{b}^{2} k_{z b} \phi_{b i}= \\
& =r_{w}\left[Y_{j,(j+1) 1}+Y_{j,(j+1) 2}\right]+e_{w}\left[Q_{j,(j+1) 1}-Q_{j,(j+1) 2}\right]+r_{w} Y_{\sigma j, j+1}
\end{aligned}
$$

where the term $J_{y w}\left(V / r_{w}\right) \dot{\alpha}_{w j, j+1}$ is given by the gyroscopic moment due to the combined effect of the yaw motion with the rotation motion of the wheelset around its own axis [26].

The wheel/rail contact forces are: the longitudinal forces, the guidance forces and the vertical loads. These are expressed as a function on the longitudinal components $T_{x j,(j+1) 1,2}$ and lateral $T_{y j,(j+1) 1,2}$ of the creep forces and the normal reactions $N_{j,(j+1) 1,2}$ in the wheel/rail contact points. For example, the equations for the wheelsets ' $j$ ' (see Fig. 3) can be therefore written

$$
\begin{aligned}
& X_{j 1,2}=T_{x j 1,2} ; \\
& Y_{j 1,2}=T_{y j 1,2} \cos \gamma_{r j 1,2} \mp N_{j 1,2} \sin \gamma_{r j 1,2} ; \\
& Q_{j 1,2}= \pm T_{y j 1,2} \sin \gamma_{r j 1,2}+N_{j 1,2} \cos \gamma_{r j 1,2},
\end{aligned}
$$

where $\gamma_{r j 1,2}$ stand for the wheel/rail contact angles against the track reference system and these is calculated with equation below

$$
\gamma_{r j 1,2}=\gamma_{w} \pm\left(y_{w j 1,2}-\zeta_{j}\right) \frac{1}{\rho_{w}-\rho_{r}} \frac{e_{w}+\rho_{w} \gamma_{w}}{e_{w}-r_{w} \gamma_{w}}
$$

where $\gamma_{w}$ is the wheel/rail contact angle for the median position of the wheelset on the track and $\rho_{w}$ and $\rho_{r}$ represent the curvature radii of the wheel-rail rolling profiles.
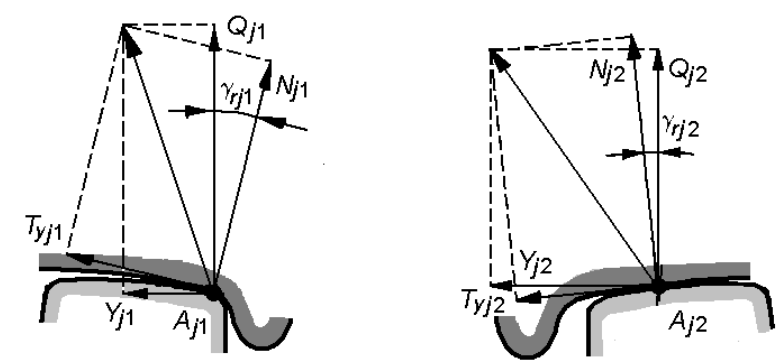

Fig. 3. Explanatory for the wheel/rail contact forces.

According to Polach's friction nonlinear model [19], the components of the creep forces have the forms

$$
\begin{aligned}
& T_{x j 1,2}=-\frac{2 \mu N_{j 1,2}}{\pi}\left(\frac{\kappa_{j 1,2}}{1+\kappa_{j 1,2}^{2}}+\operatorname{arctg} \kappa_{j 1,2}\right) \frac{v_{x j 1,2}}{v_{c j 1,2}}, \\
& T_{y j 1,2}=-\mu N_{j 1,2}\left\{\begin{array}{l}
\frac{2}{\pi}\left(\frac{\kappa_{j 1,2}}{1+\kappa_{j 1,2}^{2}}+\operatorname{arctg} \kappa_{j 1,2}\right) \frac{v_{y j 1,2}}{v_{c j 1,2}}+ \\
+\frac{9}{16} a_{j 1,2} K_{M j 1,2}\left[1+6,3\left(1-e^{(-a / b)_{j 1,2}}\right)\right] \frac{v_{s j 1,2}}{v_{c j 1,2}}
\end{array}\right\},
\end{aligned}
$$

where $\mathrm{m}$ is the friction coefficient, $\mathrm{v}_{x j 1,2}$ and $\mathrm{v}_{y j 1,2}$ is the longitudinal and the lateral components of the creepage in the wheel/rail contact points, $v_{c j 1,2}-$ the creepage corrected by the spin and $a_{j 1,2}$ and $b_{j 1,2}$ stand for the semiaxes of the contact ellipse.

The creepage in the wheel/rail contact points are calculated with the equations:

$v_{x j 1,2}=\mp \frac{y_{w j}-\zeta_{j}}{r_{w}} \gamma_{e}-\frac{\omega_{w j} r_{w}}{V} \mp \frac{e_{w} \dot{\alpha}_{w j}}{V}$

$v_{y j 1,2}=\frac{1}{V}\left(\varphi \dot{y}_{w j}-\lambda \dot{\zeta}_{j}\right)-\alpha_{w j}, \quad$ with $\quad \lambda=\frac{r_{w} \gamma_{w}}{e_{w}-r_{w} \gamma_{w}} \quad$ and

$\varphi=1+\lambda$

$v_{c j 1,2}=\sqrt{v_{x j 1,2}^{2}+v_{y c j 1,2}^{2}}$,

where $\gamma_{e}$ is the equivalent conicity and $v_{y c j 1,2}$ represents the lateral component of the creepage corrected by the spin. In order to calculate the equivalent conicity and lateral component of the creepage corrected by the spin the relations below are applied:

$$
\begin{aligned}
& \gamma_{e}=\frac{\rho_{r} \gamma_{w}}{\rho_{w}-\rho_{r}} \frac{e_{w}+\rho_{r} \gamma_{w}}{e_{w}-r_{w} \gamma_{w}} \\
& v_{y c j 1,2}=v_{y j 1,2}+a_{j 1,2} v_{s j 1,2}, \mathrm{f} \\
& \quad \text { for } \\
& \left|v_{y j 1,2}+a_{j 1,2} v_{s j 1,2}\right|>\left|v_{y j 1,2}\right|, \\
& v_{y c j 1,2}=v_{y j 1,2}, \\
& \text { for } \\
& \left|v_{y j 1,2}+a_{j 1,2} v_{s j 1,2}\right| \leq\left|v_{y j 1,2}\right|,
\end{aligned}
$$

where $v_{s j 1,2}$ is the spin, defined as

$$
v_{s j 1,2}=\frac{\dot{\alpha}_{w j}}{V} \mp\left(\frac{1}{r_{w}}+\frac{\omega_{w j}}{V}\right) \gamma_{w j 1,2}
$$

where $\gamma_{w j 1,2}$ represent the wheel/rail contact angles compared to the wheelset reference system

$$
\gamma_{w 1,2}=\gamma_{w} \pm\left(y_{w j 1,2}-\zeta_{j}\right) \frac{1}{\rho_{w}-\rho_{r}} \frac{e_{w}+\rho_{r} \gamma_{w}}{e_{w}-r_{w} \gamma_{w}}
$$

To determine the semiaxes of the wheel/rail contact ellipse, the Hertz equations will be used, as a function on the normal force and the curves of the rolling profiles [29].

The coefficient $\kappa_{j 1,2}$ (see equations (17) and (18)), it can be calculated as below

$\kappa_{j 1,2}=\frac{1}{4} \frac{G \pi a_{j 1,2} b_{j 1,2} C_{i i}}{\mu N_{j 1,2}} v_{c j 1,2}$

where $G$ is the transversal elasticity module and $C_{i i}$ is a constant which depends on the coefficients $C_{11}$ and $C_{22}$ defined by Kalker [23]: 


$$
\begin{aligned}
& C_{i i}=\sqrt{\left(C_{11} \frac{v_{x j 1,2}}{v_{j 1,2}}\right)^{2}+\left(C_{22} \frac{v_{y j 1,2}}{v_{j 1,2}}\right)^{2}}, \\
& v_{j 1,2}=\sqrt{v_{x j 1,2}^{2}+v_{y j 1,2}^{2}} .
\end{aligned}
$$

The coefficient $K_{M j 1,2}$ (see the equation (18)) is

$$
K_{M j 1,2}=\left|\kappa_{s j 1,2}\right| \cdot\left(\frac{\delta_{j 1,2}^{3}}{3}-\frac{\delta_{j 1,2}^{2}}{2}+\frac{1}{6}\right)-\frac{1}{3} \sqrt{\left(1-\delta_{j 1,2}^{2}\right)^{3}},
$$

where

$$
\delta_{j 1,2}=\frac{\kappa_{s j 1,2}^{2}-1}{\kappa_{s j 1,2}^{2}+1},
$$

for

$\kappa_{s j 1,2}=\frac{8}{3} \frac{G b_{j 1,2} \sqrt{a_{j 1,2} b_{j 1,2}}}{\mu N_{j 1,2}} \frac{C_{23} v_{y c j 1,2}}{1+2 \pi\left[1-e^{-(a / b)_{j 1,2}}\right]}$,

where $C_{23}$ is the coefficient calculated by Kalker for the spin [23].

To determine the normal reactions $N_{j 1,2}$ in the wheel/rail contact points of the wheelsets ' $j$ ' the equations (11) and (12) are written as below

$$
\begin{aligned}
& q_{j 1} N_{j 1}+q_{j 2} N_{j 2}=2 Q_{w} ; \\
& \left(r_{w} p_{j 1}-e_{w} q_{j 1}\right) N_{j 1}+\left(r_{w} p_{j 2}+e_{w} q_{j 2}\right) N_{j 2}=-c_{j},
\end{aligned}
$$

in which

$$
\begin{aligned}
& c_{j}=J_{x w} \ddot{\phi}_{w j}-J_{y w}\left(V / r_{w}\right) \dot{\alpha}_{w j}-2 b_{b}^{2} c_{z b} \dot{\phi}_{b i}-2 b_{b}^{2} k_{z b} \phi_{b i}-r_{w} Y_{\sigma j} \\
& q_{j 1,2}=1 \mp\left(K_{j 1,2} \frac{v_{y j 1,2}}{v_{c j 1,2}}+K_{s j 1,2} \frac{v_{s j 1,2}}{v_{c j 1,2}}\right) \gamma_{r j 1,2} \\
& p_{j 1,2}=K_{j 1,2} \frac{v_{y j 1,2}}{v_{c j 1,2}}+K_{s j 1,2} \frac{v_{s j 1,2}}{v_{c j 1,2}} \pm \gamma_{r j 1,2},
\end{aligned}
$$

where

$$
\begin{aligned}
& K_{j 1,2}=\frac{2 \mu}{\pi}\left(\frac{\kappa_{j 1,2}}{1+\kappa_{j 1,2}^{2}}+\operatorname{arctg} \kappa_{j 1,2}\right) \\
& K_{s j 1,2}=\frac{9 \mu}{16} a_{j 1,2} K_{M j 1,2}\left[1+6,3\left(1-e^{-(a / b)_{j 1,2}}\right)\right] .
\end{aligned}
$$

The solution of the set of non-linear equations $(32-33)$ can be derived by simple iterations via the below equations

$$
\begin{aligned}
& N_{j 1}=\frac{2\left(r_{w} p_{j 2}+e_{w} q_{j 2}\right) Q_{w}+q_{j 2} c_{j}}{r_{w}\left(q_{j 1} p_{j 2}-q_{j 2} p_{j 1}\right)+2 e_{w} q_{j 1} q_{j 2}} ; \\
& N_{j 2}=\frac{-q_{j 1} c_{j}-2\left(r_{w} p_{j 1}-e_{w} q_{j 1}\right) Q_{w}}{r_{w}\left(q_{j 1} p_{j 2}-q_{j 2} p_{j 1}\right)+2 e_{w} q_{j 1} q_{j 2}} .
\end{aligned}
$$

The equations (37) are used iteratively for each integration step in the calculation of the wheel/rail contact normal forces.

\section{The Linear Movement Equations of the Vehicle}

To express the linear movement equations of the vehicle, a starting point is the non-linear equations in the previous section, which will be linearized in line with the below procedure applied around the vehicle equilibrium position in an ideal track.

The movement equations of the carbody and bogies can be noticed to be linear (Eq. 1-6), while the wheelset movement equations ( 7 - 9) - where the creep forces and the rail lateral reaction are present - are non-linear. Similarly, the algebraic equations (37) will insert non-linear terms, based on which the normal forces on the rolling surfaces are calculated.

The linear movement equations describe the regime of the small oscillations around the balance position of the vehicle on the track. To linearize the movement equations, the lateral rail reaction that only acts upon the clearance consumption on the track will consequently be taken out $\left(Y_{\mathrm{s} j,(j+1)}=0\right)$ from the equation of yaw movement in the wheelsets (Eq. (7)).

According to Kalker's theory [23], the non-linear expressions of the creep forces for the wheelsets ' $j$ ' for small creepage $(0.001 \ldots 0.0015)$, are given in the equations

$$
\begin{aligned}
& T_{x j 1,2}=-N_{j 1,2} \chi_{x} v_{x j 1,2} ; \\
& T_{y j 1,2}=-N_{j 1,2}\left(\chi_{y} v_{y j 1,2}+\chi_{s} v_{s j 1,2}\right),
\end{aligned}
$$

where the longitudinal and lateral creepage are found in the equations (19) and (20), while the (adimensional) spin creepage comes from the relation

$v_{s j 1,2}=\frac{r_{w} \dot{\alpha}_{w j}}{V} \mp \gamma_{w j 1,2}$

The creepage coefficients $\chi_{x}, \chi_{y}$ şi $\chi_{s}$ are defined as follows:

$\chi_{x}=\frac{G a_{j 1,2} b_{j 1,2}}{N_{j 1,2}} C_{11} ; \chi_{\mathrm{y}}=\frac{G a_{j 1,2} b_{j 1,2}}{N_{j 1,2}} C_{22}$

$\chi_{\mathrm{s}}=\frac{G\left(a_{j 1,2} b_{j 1,2}\right)^{3 / 2}}{r_{w} N_{j 1,2}} C_{23}$,

in which, for linearization reasons, $N_{j 1,2}=Q_{w}, a_{j 1,2}=a$ and $b_{i 1,2}=b$ are considered, where $a$ and $b$ are the semiaxes of the contact ellipse corresponding to the load $Q_{w}$.

The parameters $q_{j 1,2}$ and $p_{j 1,2}$ (Eq. (35)) will be therefore written as:

$$
\begin{aligned}
& q_{j 1,2}=1 \mp\left(\chi_{y} v_{y j 1,2}+\chi_{s} v_{s j 1,2}\right) \gamma_{r j 1,2} \\
& p_{j 1,2}=\chi_{y} v_{y j 1,2}+\chi_{s} v_{s j 1,2} \pm \gamma_{r j 1,2} .
\end{aligned}
$$

After processing, relation (42) becomes: 


$$
\begin{aligned}
& q_{j 1,2}=1 \mp\left[\begin{array}{l}
\chi_{y}\left(\frac{\varphi \dot{y}_{w j}-\lambda \dot{\zeta}_{j}}{V}-\alpha_{w j}\right)+ \\
+\chi_{s}\left(\frac{r_{w} \dot{\alpha}_{w j}}{V} \mp \gamma_{w}-\varepsilon_{w} \frac{y_{w j}-\zeta_{j}}{e_{w}}\right)
\end{array}\right] * \\
& *\left(\gamma_{w} \pm \varepsilon_{r} \frac{y_{w j}-\zeta_{j}}{e_{w}}\right) \\
& p_{j 1,2}=\chi_{y}\left(\frac{\varphi \dot{y}_{w j}-\lambda \dot{\zeta}_{j}}{V}-\alpha_{w j}\right)+ \\
& +\chi_{s}\left(\frac{r_{w} \dot{\alpha}_{w j}}{V} \mp \gamma_{w}-\varepsilon_{w} \frac{y_{w j}-\zeta}{e_{w}}\right), \\
& \pm \gamma_{w}+\varepsilon_{r} \frac{y_{w j}-\zeta_{j}}{e_{w}} \\
& \text { for } \varepsilon_{r}=\frac{e_{w}}{\rho_{w}-\rho_{r}} \frac{e_{w}+\rho_{w} \gamma_{w}}{e_{w}-r_{w} \gamma_{w}} ; \varepsilon_{w}=\frac{e_{w}}{\rho_{w}-\rho_{r}} \frac{e_{w}+\rho_{r} \gamma_{w}}{e_{w}-r_{w} \gamma_{w}}
\end{aligned}
$$

To obtain certain linear shapes for the reactions $N_{j 1,2}$, the second degree terms will be left out in (43) - (44) and the below approximations will be considered

$$
q_{j 1,2} \cong 1 ; p_{j 1,2} \cong \pm \gamma_{w}
$$

The expressions for the reactions will be derived from (37) and (46)

$$
N_{j 1,2}=Q_{w} \pm \frac{c_{j}}{2\left(e_{w}-r_{w} \gamma_{w}\right)}
$$

where $c_{j}$ comes from (34) for $Y_{\mathrm{s} j}=0$

$$
c_{j}=J_{x w} \ddot{\phi}_{w j}-J_{y w} \frac{V}{r_{w}} \dot{\alpha}_{w j}-2 b_{b}^{2} c_{z b} \dot{\phi}_{b i}-2 b_{b}^{2} k_{z b} \phi_{b i} .
$$

The linear expressions of the contact forces can be now written:

$$
\begin{aligned}
& X_{j 1,2}=-\chi_{x} Q_{w}\left(\mp \frac{y_{w j}-\zeta_{j}}{r_{w}} \gamma_{e}-\frac{r_{w} \omega_{w j}}{V} \mp \frac{e_{w} \dot{\alpha}_{w j}}{V}\right) \\
& Y_{j 1,2}=Q_{w}\left[\begin{array}{l}
\left.\chi_{y}\left(\frac{\varphi \dot{y}_{w j}-\chi \dot{\zeta}_{j}}{V}-\alpha_{w j}\right)+\chi_{s}\left(\frac{r_{w} \dot{\alpha}_{w j}}{V} \mp \gamma_{w}-\varepsilon_{w} \frac{y_{w j}-\zeta_{j}}{e_{w}}\right)\right]+ \\
\pm \gamma_{w}+\varepsilon_{r} \frac{y_{w j}-\zeta_{j}}{e_{w}}
\end{array}\right] \\
& +\gamma_{w}\left(1-\chi_{s}\right) \frac{J_{x w} \ddot{\phi}_{w j}-J_{y w} \frac{V}{r_{w}} \dot{\alpha}_{w j}-2 b_{b}^{2} c_{z b} \dot{\phi}_{b i}-2 b_{b}^{2} k_{z b} \phi_{b i}}{2\left(e_{w}-r_{w} \gamma_{w}\right)}
\end{aligned}
$$

$$
\begin{aligned}
& Q_{j 1,2}=Q_{w}\left\{1 \mp \gamma_{w}\left[\begin{array}{l}
\chi_{y}\left(\frac{\varphi \dot{y}_{w j}-\chi \dot{\zeta}_{j}}{V}-\alpha_{w j}\right)+ \\
\chi_{s}\left(\frac{r_{w} \dot{\alpha}_{w j}}{V} \mp \gamma_{w}-\varepsilon_{w} \frac{y_{w j}-\zeta}{e_{w}}\right)
\end{array}\right]\right\} \pm \\
& \pm \frac{J_{x w} \ddot{\phi}_{w j}-J_{y w} \frac{V}{r_{w}} \dot{\alpha}_{w j}-2 b_{b}^{2} c_{z b} \dot{\phi}_{b i}-2 b_{b}^{2} k_{z b} \phi_{b i}}{2\left(e_{w}-r_{w} \gamma_{w}\right)}
\end{aligned}
$$

The linearized movement equations of the wheelsets are:

- the yaw movement equation

$$
\begin{aligned}
& m_{w} \ddot{y}_{w j,(j+1)}+2 c_{y b}\left[\dot{y}_{w j,(j+1)}-\dot{y}_{b i}-h_{b 1} \dot{\phi}_{b i} \mp a_{b} \dot{\alpha}_{b i}\right]+ \\
& +2 k_{y b}\left[y_{w j,(j+1)}-y_{b i}-h_{b 1} \phi_{b i} \mp a_{b} \alpha_{b i}\right]+ \\
& +2 \varphi \frac{\chi_{y} Q_{w}}{V} \dot{y}_{w j,(j+1)}+2 \frac{\chi_{s} r_{w} Q_{w}}{V} \dot{\alpha}_{w j,(j+1)}- \\
& -J_{y w} \frac{\gamma_{w} V}{r_{w}} \frac{1-\chi_{s}}{e_{w}-r_{w} \gamma_{w}} \dot{\alpha}_{w j,(j+1)}+ \\
& +2 Q_{w} \varepsilon_{r} \frac{1-\chi_{s} \varepsilon_{w}}{e_{w}} y_{o j,(j+1)}-2 \chi_{y} Q_{w} \alpha_{w j,(j+1)}- \\
& -2 \gamma_{w}\left(1-\chi_{s}\right) \frac{b_{b}^{2} c_{z b}}{e_{w}-r_{w} \gamma_{w}} \dot{\phi}_{b i}- \\
& -2 \gamma_{w}\left(1-\chi_{s}\right) \frac{b_{b}^{2} k_{z b}}{e_{w}-r_{w} \gamma_{w}} \phi_{b i}=2 \lambda \frac{\chi_{y} Q_{w}}{V} \dot{\zeta}_{j,(j+1)}+ \\
& +2 Q_{w} \varepsilon_{r} \frac{1-\chi_{s} \varepsilon_{w}}{e_{w}} \zeta_{j,(j+1)}
\end{aligned}
$$

only to mention that the inertial term due to the wheelset roll $\frac{\gamma_{w}\left(1-\kappa_{s}\right) J_{x w}}{e_{w}-r_{w} \gamma_{w}} \ddot{\phi}_{w j}$ has been left out, since it is much smaller than the influence of the wheelset mass.

- the hunting movement equation

$$
\begin{aligned}
& J_{z w} \ddot{\alpha}_{w j,(j+1)}+2 c_{x b} b_{b}^{2}\left(\dot{\alpha}_{w j,(j+1)}-\dot{\alpha}_{b i}\right)+2 k_{x b} b_{b}^{2}\left(\alpha_{w j,(j+1)}-\alpha_{b i}\right)+ \\
& +J_{y w} \frac{V}{r_{w}^{2}} \lambda\left(\dot{y}_{w j,(j+1)}-\dot{\zeta}_{j,(j+1)}\right)+2 \chi_{x} Q_{w}\left(\frac{e_{w} \gamma_{e}}{r_{w}} y_{w j,(j+1)}+\frac{e_{w}^{2}}{V} \dot{\alpha}_{w j,(j+1)}\right)= \\
& =2 \chi_{x} Q_{w} \frac{e_{w} \gamma_{e}}{r_{w}} \zeta_{j,(j+1)} .
\end{aligned}
$$

- the wheelset rotation movement around its own axis

$J_{y w} \dot{\omega}_{w j}+2 \chi_{x} \frac{r_{w}^{2} Q_{w}}{V} \omega_{w j}=0$

Following the linearization, the rotation movement around its own axis is noticed to become independent.

\section{Numerical Analysis}

In order to establish the applicability domain of the linear models within the lateral dynamics of the railway vehicles, 
this section will focus on a series of results obtained from numerical simulations developed on the models presented in the previous sections in this paper.

The compared parameters are the lateral accelerations calculated in three carbody reference points (at the carbody centre and above the bogies) during the running of the vehicle on a track with lateral irregularities: a) in a harmonic shape; b) isolated defect-type; c) random shape.

The parameters of the numeric model are featured in Table 1 and are representatives for a passenger vehicle. To calculate the geometrical parameters of the wheel/rail contact, the S78 profile wheel and the UIC 60 rail with the standard cant at C.F.R. of $1 / 20$ are considered (see Table 2) [30].

Table 1. The parameters of the numerical model.

\begin{tabular}{c|c}
\hline$m_{c}=34000 \mathrm{~kg} ;$ & $2 c_{x c}=50 \mathrm{kNs} / \mathrm{m}$ \\
\hline$m_{b}=3200 \mathrm{~kg}$ & $c_{y c}=15.205 \mathrm{kNs} / \mathrm{m}$ \\
\hline$m_{w}=1650 \mathrm{~kg}$ & $2 c_{z c}=34.44 \mathrm{kNs} / \mathrm{m}$ \\
\hline$J_{x c}=57460 \mathrm{kgm}^{2}$ & $2 k_{x c}=340 \mathrm{kN} / \mathrm{m}$ \\
\hline$J_{z c}=2456500 \mathrm{kgm}^{2}$ & $2 k_{y c}=340 \mathrm{kN} / \mathrm{m}$ \\
\hline$J_{x b}=3200 \mathrm{kgm}^{2}$ & $2 k_{z c}=1.2 \mathrm{MN} / \mathrm{m}$ \\
\hline$J_{z b}=5000 \mathrm{kgm}^{2}$ & $k_{\varphi c}=10 \mathrm{kNm}$ \\
\hline$J_{x w}=J_{z w}=928.125 \mathrm{kgm}^{2}$ & $4 c_{x b}=100 \mathrm{kNs} / \mathrm{m}$ \\
\hline$J_{y w}=349.14 \mathrm{kgm}^{2}$ & $4 c_{y b}=35.77 \mathrm{kNs} / \mathrm{m}$ \\
\hline $2 a_{c}=19 \mathrm{~m}$ & $4 c_{z b}=52.21 \mathrm{kNs} / \mathrm{m}$ \\
\hline $2 a_{b}=2.56 \mathrm{~m}$ & $4 k_{x b}=140 \mathrm{MN} / \mathrm{m}$ \\
\hline$h_{c}=1.3 \mathrm{~m}$ & $4 k_{y b}=10 \mathrm{MN} / \mathrm{m}$ \\
\hline$h_{b 1}=0.25 \mathrm{~m} ; h_{b 2}=0.2 \mathrm{~m}$ & $4 k_{z b}=4.4 \mathrm{MN} / \mathrm{m}$ \\
\hline $2 b_{b}=2 b_{c}=2 \mathrm{~m}$ & $k_{y r}=100 \mathrm{MN} / \mathrm{m}$ \\
\hline$\sigma=12 \mathrm{~mm}$ & $\mathrm{~m}=0.36$ \\
\hline
\end{tabular}

Table 2. The geometrical parameters of the wheel/rail contact.

\begin{tabular}{|l|l|}
\hline $\mathrm{r}_{w}=0.500 \mathrm{~m} ; \mathrm{r}_{r}=0.300 \mathrm{~m}$ & $\mathrm{~g}_{w}=0.0495$ \\
\hline$e_{w}=0.754 \mathrm{~m} ; r_{w}=0.4598 \mathrm{~m}$ & $\gamma_{e}=0.1237$ \\
\hline
\end{tabular}

The critical speed of the vehicle of $261.56 \mathrm{~km} / \mathrm{h}$ derives from the values in Tables 1 and 2 [20].

The validity limits of the linear model should be firstly established, which involves the determination of the running conditions corresponding to which the creepage in the wheel-rail contact points are sufficiently low $(<0.0015)$ so that the linear theory underlining the model be applicable.

To calculate the creepage in the wheel-rail contact points, the relation below applies

$$
\begin{aligned}
& v_{j,(j+1) 1,2}=\sqrt{v_{x j,(j+1) 1,2}^{2}+v_{y j,(j+1) 1,2}^{2}} \text {, for } j=2 i-1, \\
& \text { with } i=1,2 .
\end{aligned}
$$

a) Track lateral irregularities in a harmonic shape
The lateral irregularities of the track are considered harmonic with the wavelength $\Lambda$ and amplitude $\zeta_{0}$, in the form of

$$
\zeta(x)=\zeta_{0} \cos \frac{2 \pi}{\Lambda} x
$$

where the position of the coordinate $x=V t$ corresponds to the middle of the vehicle.

The track irregularities are out of phase in conformity with the vehicle wheelbase against each wheelset,

$$
\begin{aligned}
& \zeta_{1,2}(x)=\zeta_{0} \cos \frac{2 \pi}{\Lambda}\left(x+a_{c} \pm a_{b}\right) \\
& \zeta_{3,4}(x)=\zeta_{0} \cos \frac{2 \pi}{\Lambda}\left(x-a_{c} \pm a_{b}\right)
\end{aligned}
$$

The functions $\zeta_{j,(j+1)}$, with $j=2 i-1$ for $i=1,2$, can be expressed as time harmonic functions

$$
\begin{aligned}
& \zeta_{1,2}(x)=\zeta_{0} \cos \omega\left(t+\frac{a_{c} \pm a_{b}}{V}\right) \\
& \zeta_{3,4}(x)=\zeta_{0} \cos \omega\left(t-\frac{a_{c} \mp a_{b}}{V}\right)
\end{aligned}
$$

in which $\mathrm{w}=2 \pi V / \Lambda$ represents the angular frequency induced by the track excitation ( $\mathrm{w}=2 \pi f$, where $f$ is the excitation frequency).

The wavelength of the track lateral irregularities is adopted so that the excitation frequency coincides with the frequencies that dominate the power spectral density of the carbody acceleration, which become important in terms of the dynamic behaviour of the vehicle. It is about the natural frequencies of the coupled movement of yaw-roll $(0.46 \mathrm{~Hz}$ and $1.21 \mathrm{~Hz})$ and the carbody hunting frequency $(0.78 \mathrm{~Hz})$ [21]. As for the amplitude of the lateral irregularities, values between $0.1 \ldots 2 \mathrm{~mm}$ will be used.

The Fig. 4 (for $V=100 \mathrm{~km} / \mathrm{h}$ ) and Fig. 5 (for $V=200$ $\mathrm{km} / \mathrm{h}$ ) feature the values of the creepage in the wheel-rail contact points during running on a track with lateral irregularities of a harmonic shape, with the above-mentioned characteristics. The limits of the applicability domain of the vehicle linear model can be noticed to change along with velocity and excitation frequency. At the speed of $100 \mathrm{~km} / \mathrm{h}$ (Fig. 4), the linear model can be applied for the excitation frequencies already considered unless the amplitude of the track irregularities exceeding $1 \mathrm{~mm}$. For a velocity of 200 $\mathrm{km} / \mathrm{h}$ (Fig. 5), at excitation frequencies corresponding to the low frequency of the coupled movement of yaw-roll, the model can be applied for amplitudes of the track irregularities of up to $1 \mathrm{~mm}$. Should the excitation frequency is $0.78 \mathrm{~Hz}$, equal to the carbody hunting frequency, or 1.21 $\mathrm{Hz}$ - equal to the high frequency of the coupled movement of yaw-roll, the linear model is then valid for amplitudes of the track irregularities lower than $0.5 \mathrm{~mm}$. 

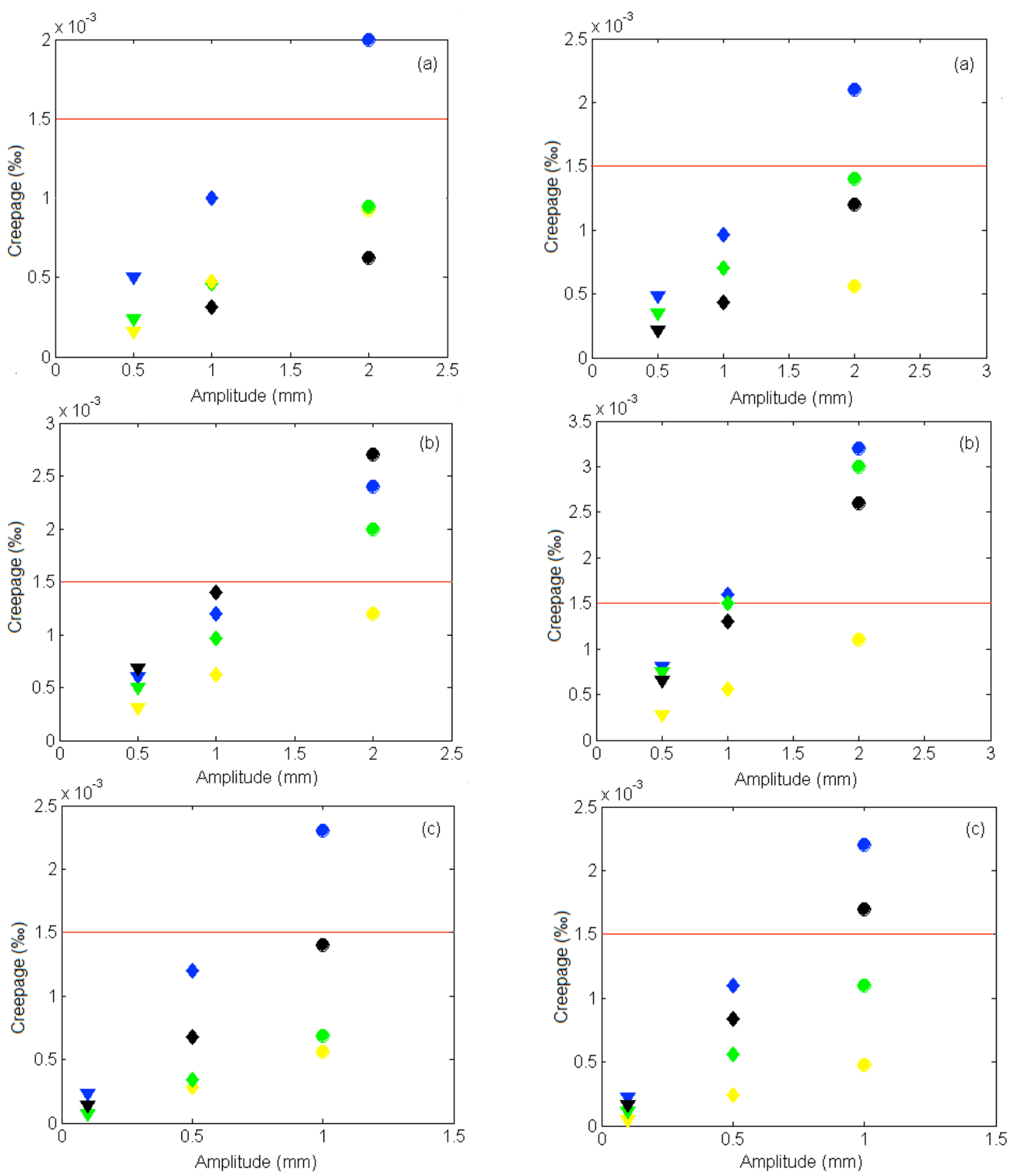

Fig. 4. Wheelset creepage for $V=100 \mathrm{~km} / \mathrm{h}$ : (a) $0.46 \mathrm{~Hz}$; (b) 0.78 Hz; (c) $1.21 \mathrm{~Hz} . \quad, 1$ wheelset; —, 2 wheelset; —, 3 wheelset; —, 4 wheelset.

Fig. 5. Wheelset creepage for $V=200 \mathrm{~km} / \mathrm{h}$ : (a) $0.46 \mathrm{~Hz}$; (b) $0.78 \mathrm{~Hz}$; (c) $1.21 \mathrm{~Hz} . \quad, 1$ wheelset; —, 2 wheelset; -, 3 wheelset; -, 4 wheelset. 
Once determined the applicability limits of the linear model, it is interesting to see to what extent the derived results are comparable to the results reached by using the non-linear model of the vehicle. The Tables 3 - 4 show the maximum values of the accelerations in three reference points (at the carbody centre and above the two bogies), coming from the use of the two models. It is obvious that the previous cases have been taken into account and for each the study has been narrowed down to the domain for which the linear model is applicable. A good correspondence between the results from the two models is visible.

Table 3. The maximum values for the carbody acceleration at $100 \mathrm{~km} / \mathrm{h}$ velocity

\begin{tabular}{|c|c|c|c|c|c|c|c|c|}
\hline \multirow{3}{*}{$\begin{array}{c}\text { Frequency } \\
\text { excitation } \\
(\mathrm{Hz})\end{array}$} & \multirow{3}{*}{$\begin{array}{c}\text { Wavelength } \\
\Lambda \text { (m) }\end{array}$} & \multirow{3}{*}{$\begin{array}{c}\text { Amplitude } \\
\zeta_{0}(\mathrm{~mm})\end{array}$} & \multirow{2}{*}{\multicolumn{3}{|c|}{$\frac{\text { Linear model }}{\text { Acceleration }\left(\mathrm{m} / \mathrm{s}^{2}\right)}$}} & \multirow{2}{*}{\multicolumn{3}{|c|}{$\frac{\text { Non-linear model }}{\text { Acceleration }\left(\mathrm{m} / \mathrm{s}^{2}\right)}$}} \\
\hline & & & & & & & & \\
\hline & & & $\begin{array}{c}\text { at the } \\
\text { carbody } \\
\text { centre }\end{array}$ & $\begin{array}{c}\text { above the } \\
\text { front } \\
\text { bogie }\end{array}$ & $\begin{array}{l}\text { above the } \\
\text { rear bogie }\end{array}$ & $\begin{array}{c}\text { at the } \\
\text { carbody } \\
\text { centre }\end{array}$ & $\begin{array}{c}\text { above the } \\
\text { front } \\
\text { bogie }\end{array}$ & $\begin{array}{l}\text { above the } \\
\text { rear bogie }\end{array}$ \\
\hline \multirow{3}{*}{0.46} & \multirow{3}{*}{60.98} & 1 & 0.0205 & 0.0100 & 0.0317 & 0.0207 & 0.0101 & 0.0319 \\
\hline & & 0.5 & 0.0103 & 0.0050 & 0.0159 & 0.0104 & 0.0050 & 0.0160 \\
\hline & & 0.1 & 0.0021 & 0.0009 & 0.0032 & 0.0021 & 0.0010 & 0.0032 \\
\hline \multirow{3}{*}{0.78} & \multirow{3}{*}{35.61} & 1 & 0.0222 & 0.1347 & 0.1377 & 0.0221 & 0.1367 & 0.1395 \\
\hline & & 0.5 & 0.0011 & 0.0674 & 0.0688 & 0.0011 & 0.0683 & 0.0697 \\
\hline & & 0.1 & 0.0002 & 0.0135 & 0.0138 & 0.0002 & 0.0137 & 0.0139 \\
\hline \multirow{2}{*}{1.21} & \multirow{2}{*}{22.95} & 0.5 & 0.0819 & 0.0668 & 0.0971 & 0.0820 & 0.0669 & 0.0972 \\
\hline & & 0.1 & 0.0164 & 0.0134 & 0.0194 & 0.0164 & 0.0134 & 0.0194 \\
\hline
\end{tabular}

Table 4. The maximum values of the carbody lateral acceleration at $200 \mathrm{~km} / \mathrm{h}$ velocity

\begin{tabular}{|c|c|c|c|c|c|c|c|c|}
\hline \multirow{3}{*}{$\begin{array}{l}\text { Frequency } \\
\text { excitation } \\
(\mathrm{Hz})\end{array}$} & \multirow{3}{*}{$\begin{array}{c}\text { Wavelength } \\
\Lambda \text { (m) }\end{array}$} & \multirow{3}{*}{$\begin{array}{c}\text { Amplitude } \\
\zeta_{0}(\mathrm{~mm})\end{array}$} & \multirow{2}{*}{\multicolumn{3}{|c|}{$\begin{array}{c}\text { Linear model } \\
\text { Acceleration }\left(\mathrm{m} / \mathrm{s}^{2}\right)\end{array}$}} & \multirow{2}{*}{\multicolumn{3}{|c|}{$\frac{\text { Non-linear model }}{\text { Acceleration }\left(\mathrm{m} / \mathrm{s}^{2}\right)}$}} \\
\hline & & & & & & & & \\
\hline & & & $\begin{array}{c}\text { at the } \\
\text { carbody } \\
\text { centre }\end{array}$ & $\begin{array}{c}\text { above the } \\
\text { front } \\
\text { bogie }\end{array}$ & $\begin{array}{l}\text { above the } \\
\text { rear bogie }\end{array}$ & $\begin{array}{l}\text { at the } \\
\text { carbody } \\
\text { centre }\end{array}$ & $\begin{array}{c}\text { above the } \\
\text { front } \\
\text { bogie }\end{array}$ & $\begin{array}{l}\text { above the } \\
\text { rear bogie }\end{array}$ \\
\hline \multirow{3}{*}{0.46} & \multirow{3}{*}{120.77} & 1 & 0.0310 & 0.0251 & 0.0370 & 0.0310 & 0.0250 & 0.0370 \\
\hline & & 0.5 & 0.0155 & 0.0125 & 0.0185 & 0.0155 & 0.0125 & 0.0185 \\
\hline & & 0.1 & 0.0031 & 0.0025 & 0.0037 & 0.0031 & 0.0025 & 0.0037 \\
\hline \multirow{2}{*}{0.78} & \multirow{2}{*}{71.22} & 0.5 & 0.0068 & 0.0502 & 0.0376 & 0.0068 & 0.0505 & 0.0378 \\
\hline & & 0.1 & 0.0014 & 0.0100 & 0.0075 & 0.0014 & 0.0101 & 0.0076 \\
\hline \multirow{2}{*}{1.21} & \multirow{2}{*}{45.91} & 0.5 & 0.0196 & 0.0433 & 0.0168 & 0.0199 & 0.0438 & 0.0168 \\
\hline & & 0.1 & 0.0039 & 0.0087 & 0.0014 & 0.0040 & 0.0088 & 0.0014 \\
\hline
\end{tabular}

The Fig. 6 - 8 include the carbody lateral accelerations while running at $200 \mathrm{~km} / \mathrm{h}$ speed, on a track with the amplitude of the harmonic irregularities of $\zeta_{0}=0.5 \mathrm{~mm}$ and various wavelengths: $\Lambda=120.77 \mathrm{~m}$ (corresponding to the excitation frequency of $0.46 \mathrm{~Hz}) ; \Lambda=71.22 \mathrm{~m}$ (corresponding to the excitation frequency of $0.78 \mathrm{~Hz}$ ); $\Lambda=$ $45.91 \mathrm{~m}$ (corresponding to the excitation frequency of 1.21 $\mathrm{Hz}$ ). What is obvious is the harmonic shape of the accelerations, which proves the permanent regime of vibration. At frequency of $0.46 \mathrm{~Hz}$, the accelerations in those three carbody reference points are in phase. For the frequencies of $0.78 \mathrm{~Hz}$ and $1.21 \mathrm{~Hz}$, the acceleration at the carbody centre is in phase only with the acceleration above the front bogie.

As for the level of vibrations in the carbody reference points, it changes as a function of the excitation frequency and the wavelength of the track lateral irregularities respectively, in the same direction for both models. To further examine this aspect, the concept of carbody critical point is introduced, as being that reference point where the level of vibrations is the highest (calculated on the basis of lateral acceleration).

Should the excitation frequency coincides with the natural law frequency of the coupled movement of yaw-roll $(0.46 \mathrm{~Hz})$, then the maximum value of acceleration is found above the rear bogie, which thus becomes the carbody critical point; the acceleration will be at is lowest value above the front bogie (Fig. 6). In case the excitation frequency is equal with the carbody hunting frequency $(0.78$ $\mathrm{Hz}$ ), the highest value of the lateral acceleration occurs above the front bogie and the lowest at the carbody centre (Fig. 7). For the natural high frequency of the coupled movement of yaw-roll $(1.21 \mathrm{~Hz})$, the critical point remains above the front bogie, while the lowest acceleration is above the rear bogie (Fig. 8). 

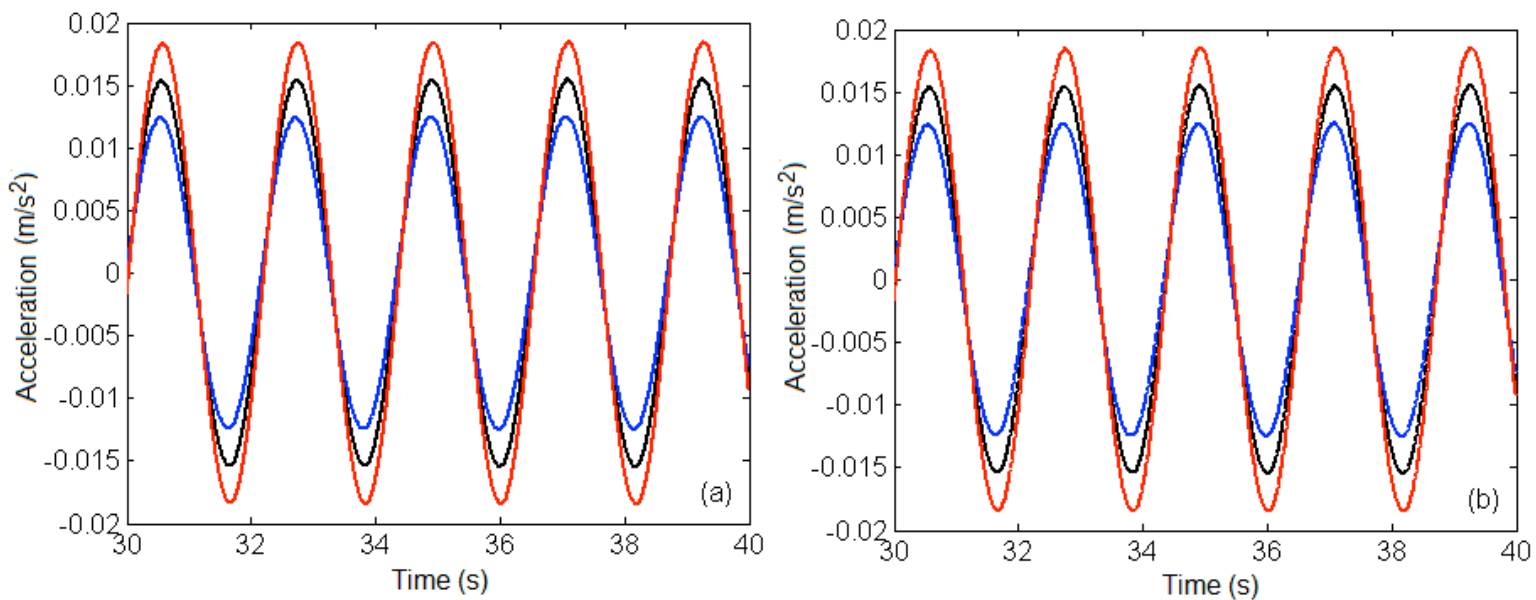

Fig. 6. Carbody lateral acceleration during running on a track with lateral irregularities of a harmonic shape $\left(\Lambda=120.77 \mathrm{~m}, \zeta_{0}=0.5 \mathrm{~mm}\right)$ : (a) linear model; (b) non-linear model; _- at the carbody centre; — - above the front bogie; — , above the rear bogie.
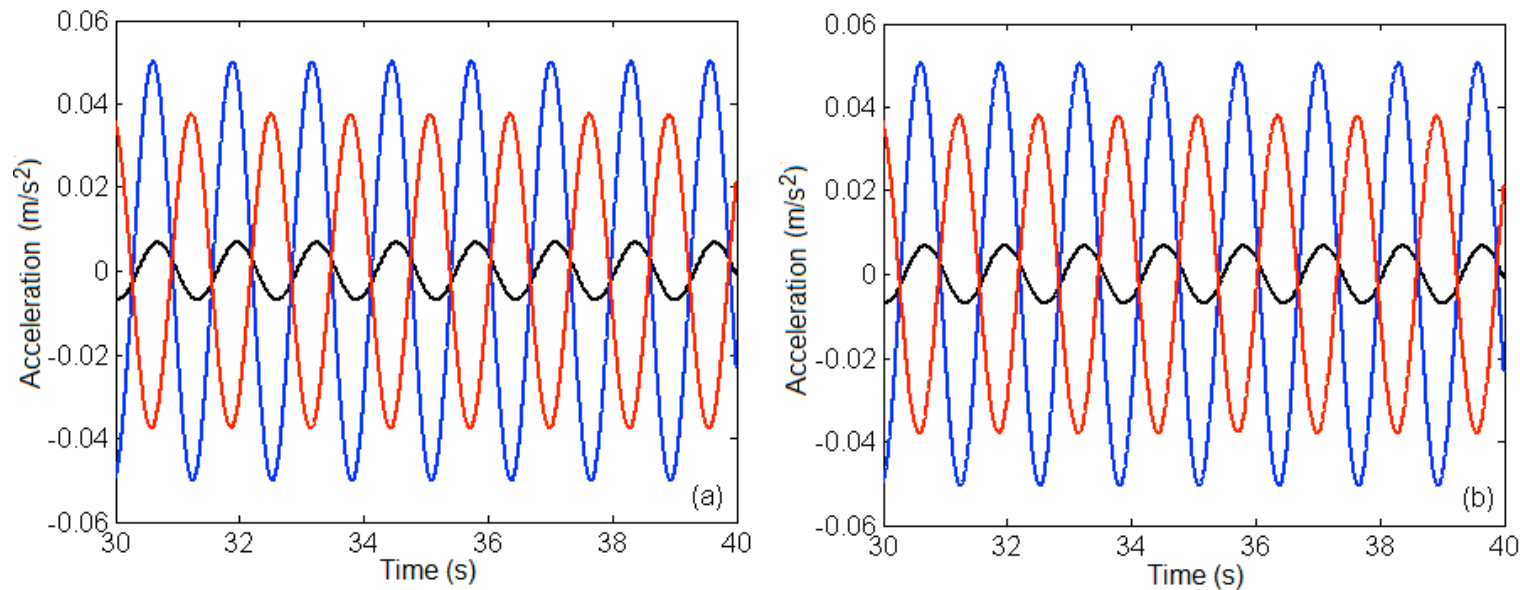

Fig. 7. Carbody lateral acceleration during running on a track with lateral irregularities of a harmonic shape $\left(\Lambda=71.22 \mathrm{~m}, \zeta_{0}=0.5 \mathrm{~mm}\right)$ : (a) linear model; (b) non-linear model; —-, at the carbody centre; - - above the front bogie; - - above the rear bogie.
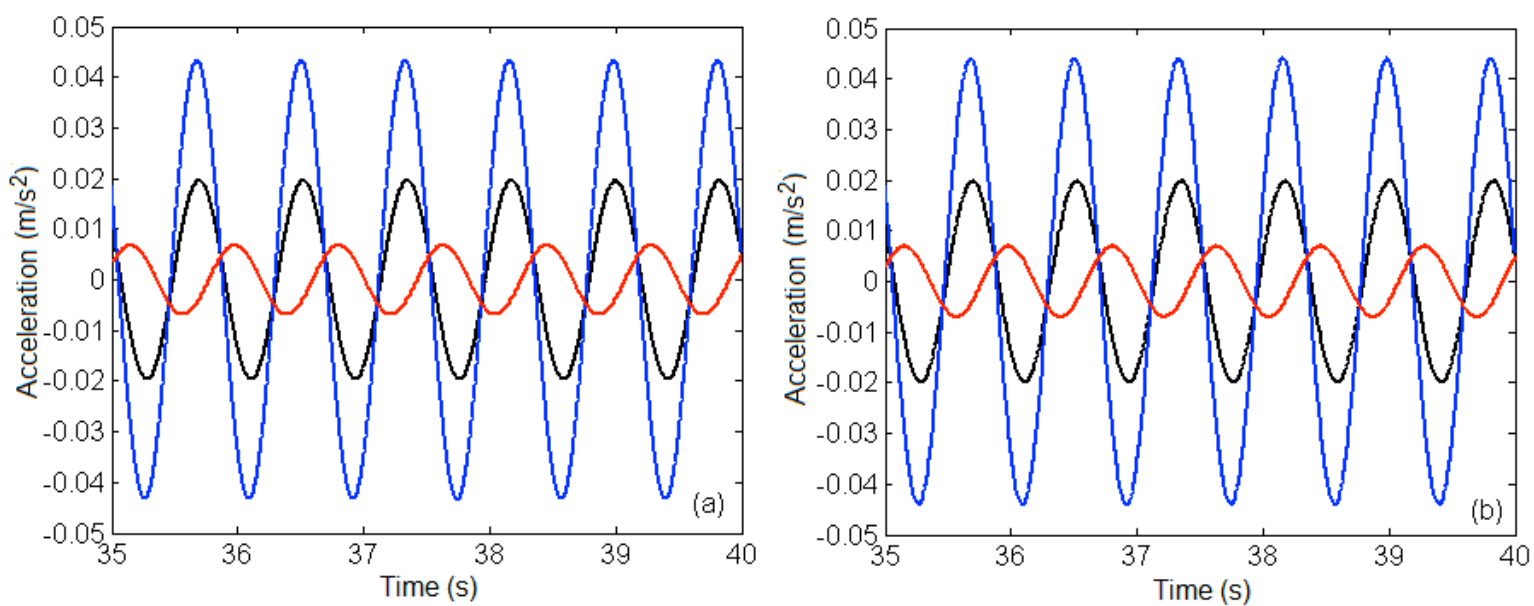

Fig. 8. Carbody lateral acceleration during running on a track with lateral irregularities of a harmonic shape $\left(\Lambda=45.91 \mathrm{~m}, \zeta_{0}=0.5 \mathrm{~mm}\right)$ : (a) linear model; (b) non-linear model; — - at the carbody centre; — , above the front bogie; — , above the rear bogie.

b) Lateral irregularities of the track, corresponding to isolated defects

Against each wheelset, the isolated defect can be analytically described in a function such as below:

$\zeta_{j,(j+1)}\left(x_{j,(j+1)}\right)=\zeta_{0} \sin ^{2}\left(\pi x_{j,(j+1)} / \Lambda\right), \quad$ for $0 \leq x_{j,(j+1)} \leq$ $\mathrm{L}$; $\zeta_{j,(j+1)}\left(x_{j,(j+1)}\right)=0$, for $x_{j,(j+1)}<0$ or $x_{j,(j+1)}>\mathrm{L}$,

where, depending on the wheelset position within the vehicle, $x_{j,(j+1)}$ is: 
where abscissa $x$ is calculated in dependence on the moment $t, x=V t$.

The wavelength $\mathrm{L}=10 \mathrm{~m}$ is considered for this case; according to the UIC 518 Leaflet [31], and as for the defect amplitude, unless the velocity exceeds $200 \mathrm{~km} / \mathrm{h}, \zeta_{0}=4 \mathrm{~mm}$ can be adopted for a QN1 quality track; for a QN2 track, the value of $\zeta_{0}$ is $6 \mathrm{~mm}$.

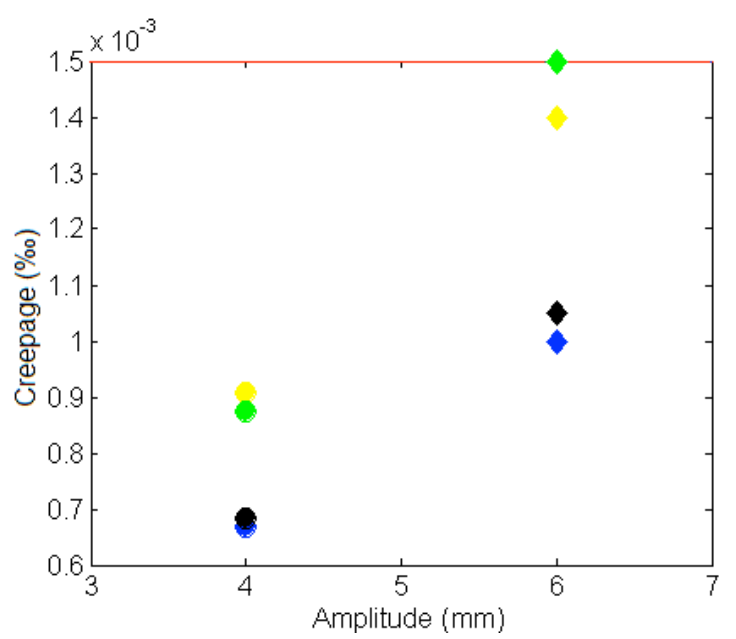

Fig. 9. Wheelset creepage for $V=100 \mathrm{~km} / \mathrm{h}$ :

, 1 wheelset; -2 , wheelset;

,- 3 wheelset; —, 4 wheelset.

The Table 5 features the maximum values of the lateral accelerations in the carbody reference points at velocities of $100 \mathrm{~km} / \mathrm{h}$ and $200 \mathrm{~km} / \mathrm{h}$, derived from using the two models, whereas the Fig. 11 and 12 show a time history of the carbody lateral accelerations upon passing over an isolated defect with a $6 \mathrm{~mm}$-amplitude. While using the linear model of the vehicle, higher values of acceleration are noticed, as well as the fact that the differences between the results from the two models increase along with the velocity and the
When following a similar methodology with the running on a track with lateral irregularities in a harmonic shape for establishing the applicability domain of the linear model, the creepage will be calculated in the wheel-rail contact points and conditions will be set forth for which these results do not exceed 0.0015. As seen in Fig. 9 and Fig. 10, these conditions are complied with for all the situations being examined.

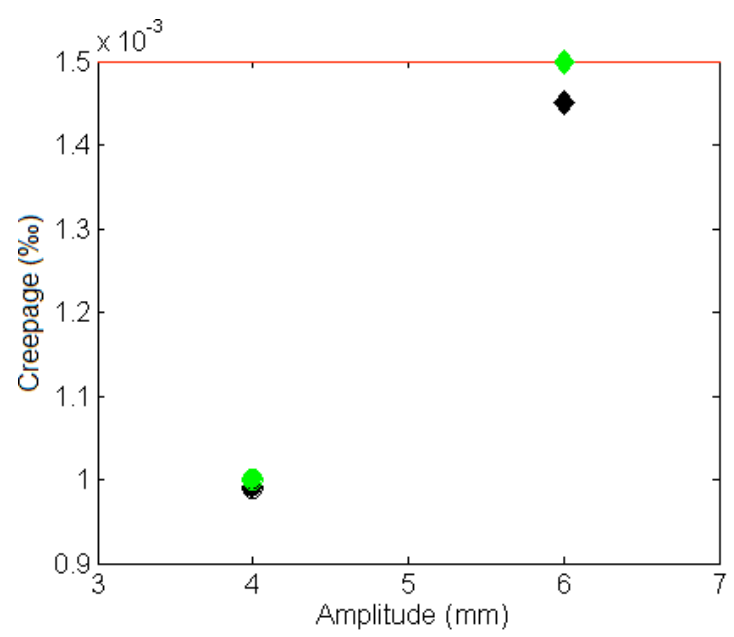

Fig. 10. Wheelset creepage for $V=200 \mathrm{~km} / \mathrm{h}$ :

- 1 wheelset and 3 wheelset;

- 2 wheelset and 4 wheelset.

amplitude of the isolated defect. For instance, if referring to the maximum acceleration calculated at the carbody centre, it can be proved that there occur the following differences between the results derived from the linear model and nonlinear model of the vehicle: for $\zeta_{0}=4 \mathrm{~mm}-5.79 \%$, at 100 $\mathrm{km} / \mathrm{h} ; 10.02 \%$, at $200 \mathrm{~km} / \mathrm{h}$; for $\zeta_{0}=6 \mathrm{~mm}-9.07 \%$, at 100 $\mathrm{km} / \mathrm{h} ; 15.90 \%$, at $200 \mathrm{~km} / \mathrm{h}$.

Table 5. The maximum values of the carbody lateral acceleration during running on a track with lateral irregularities corresponding to isolated defects

\begin{tabular}{|c|c|c|c|c|c|c|c|}
\hline \multirow{3}{*}{$\begin{array}{c}\text { Amplitude of } \\
\text { the isolated } \\
\text { defect } \\
\zeta_{0}(\mathrm{~mm})\end{array}$} & \multirow{3}{*}{$\begin{array}{l}\text { Velocity } \\
(\mathrm{km} / \mathrm{h})\end{array}$} & \multirow{2}{*}{\multicolumn{3}{|c|}{$\begin{array}{c}\text { Linear model } \\
\text { Acceleration }\left(\mathrm{m} / \mathbf{s}^{2}\right)\end{array}$}} & \multirow{2}{*}{\multicolumn{3}{|c|}{$\begin{array}{l}\text { Non-linear model } \\
\text { Acceleration }\left(\mathrm{m} / \mathbf{s}^{2}\right)\end{array}$}} \\
\hline & & & & & & & \\
\hline & & $\begin{array}{c}\text { at the } \\
\text { carbody } \\
\text { centre }\end{array}$ & $\begin{array}{l}\text { above the } \\
\text { front bogie }\end{array}$ & $\begin{array}{l}\text { above the } \\
\text { rear bogie }\end{array}$ & $\begin{array}{l}\text { at the } \\
\text { carbody } \\
\text { centre }\end{array}$ & $\begin{array}{l}\text { above the } \\
\text { front bogie }\end{array}$ & $\begin{array}{l}\text { above the } \\
\text { rear bogie }\end{array}$ \\
\hline 4 & $\begin{array}{l}100 \\
200\end{array}$ & $\begin{array}{l}0.1754 \\
0.1943\end{array}$ & $\begin{array}{l}0.1877 \\
0.2196\end{array}$ & $\begin{array}{l}0.2787 \\
0.2192\end{array}$ & $\begin{array}{l}0.1658 \\
0.1766\end{array}$ & $\begin{array}{l}0.1751 \\
0.2651\end{array}$ & $\begin{array}{l}0.2652 \\
0.2611\end{array}$ \\
\hline 6 & $\begin{array}{l}100 \\
200 \\
\end{array}$ & $\begin{array}{l}0.2631 \\
0.2915 \\
\end{array}$ & $\begin{array}{l}0.2815 \\
0.4372\end{array}$ & $\begin{array}{l}0.4180 \\
0.4353\end{array}$ & $\begin{array}{l}0.2412 \\
0.2515\end{array}$ & $\begin{array}{l}0.2519 \\
0.3806\end{array}$ & $\begin{array}{l}0.3826 \\
0.3780 \\
\end{array}$ \\
\hline
\end{tabular}

As for the position of the carbody critical point in terms of the level of vibrations, it can be immediately identified above the rear bogie at velocity of $100 \mathrm{~km} / \mathrm{h}$, both during running on a QN1 quality track QN1 $\left(\zeta_{0}=4 \mathrm{~mm}\right)$ or QN2 $\left(\zeta_{0}=6 \mathrm{~mm}\right)$, irrespective of the applied model. At the velocity of $200 \mathrm{~km} / \mathrm{h}$, the acceleration above the two bogies will have close value, a reason for which the vehicle carbody has two critical points. 

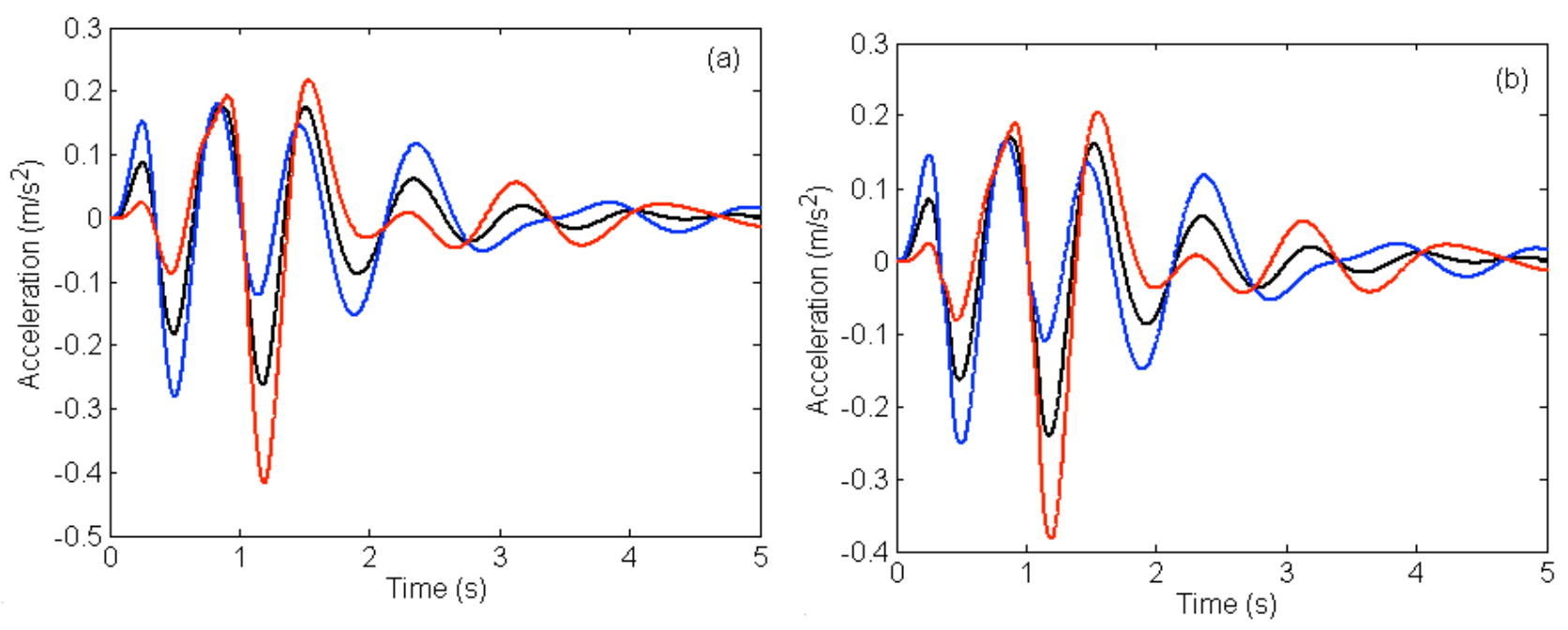

Fig. 11. Carbody lateral acceleration during passing over an isolated defect at velocity of $100 \mathrm{~km} / \mathrm{h}$, with a 6 mm-amplitude: (a) linear model; (b) nonlinear model—, at the carbody centre; - , above the front bogie; $-\frac{}{-}$, above the rear bogie.
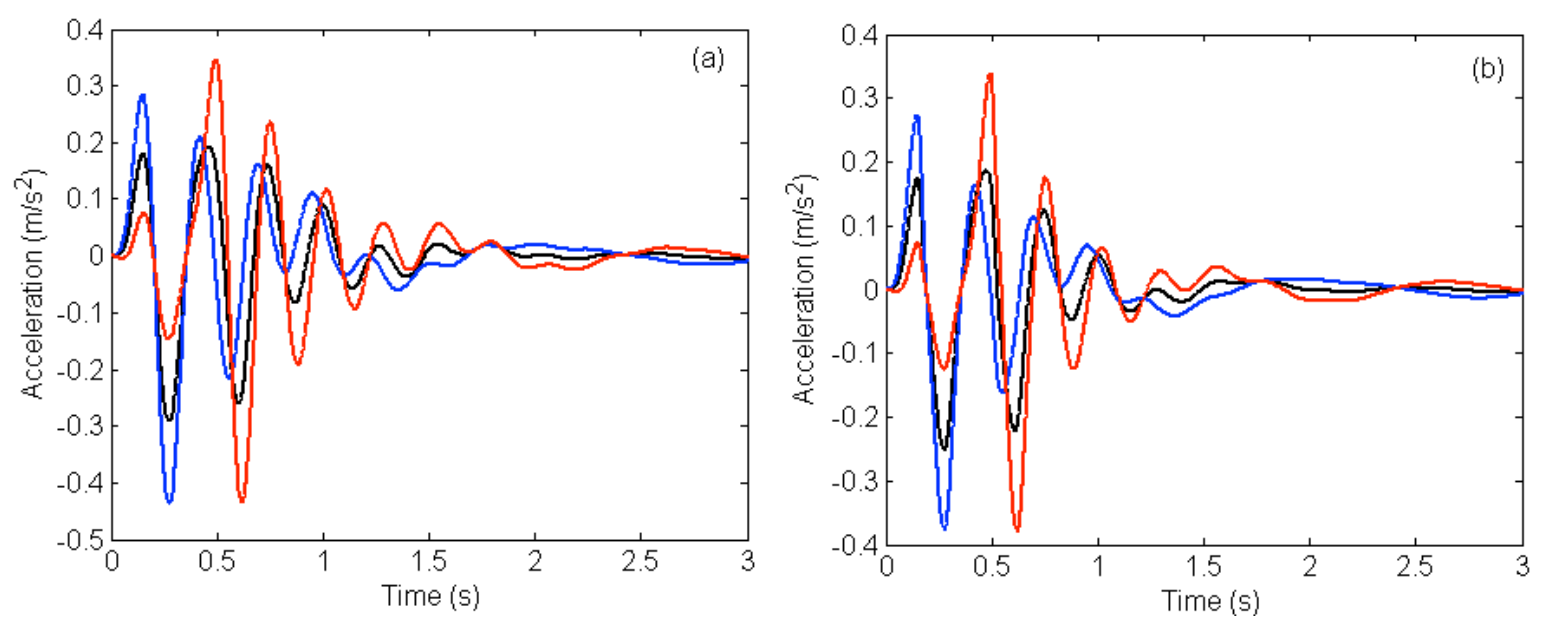

Fig. 12. Carbody lateral acceleration during passing over an isolated defect at velocity of $200 \mathrm{~km} / \mathrm{h}$, with a 6 mm-amplitude: (a) linear model; (b) nonlinear model $\_$, at the carbody centre; $-\frac{-}{-}$, above the front bogie; $-\frac{}{-}$, above the rear bogie.

c) Track lateral irregularities in a random shape

The track lateral irregularities are described by a pseudostochastic function $\zeta(x)$, written as [32]

$\zeta(x)=K_{\zeta} f(x) \sum_{k=0}^{N} U_{k} \cos \left(\Omega_{k} x+\phi_{k}\right)$

with $K_{\zeta}=\frac{\zeta_{a d m}}{\max \left|f(x) \sum_{k=0}^{N} U_{k} \cos \left(\Omega_{k} x+\phi_{k}\right)\right|}$,

where: $K_{\zeta}$ is a scaling coefficient of the amplitudes in the track lateral irregularities, $\zeta_{\text {adm }}$ is the maximum value of the track lateral irregularities as per UIC 518 Leaflet [31]; $f(x)$ is an adjustment function applied on the distance $L_{0}$, in the form of

$$
\begin{aligned}
& f(x)=\left[6\left(\frac{x}{L_{0}}\right)^{5}-15\left(\frac{x}{L_{0}}\right)^{4}+10\left(\frac{x}{L_{0}}\right)^{3}\right], \\
& * H\left(L_{0}-x\right)+H\left(x-L_{0}\right)
\end{aligned}
$$

where $H($.$) is the Heaviside's unit step function; U_{k}$ is the amplitude of the spectral component corresponding to the wave number $\mathrm{W}_{k}$, and $\mathrm{j}_{k}$ is the lag of the spectral component ,$k^{\prime}$ for which a uniform random distribution is selected. The amplitude of each spectral component is established on the basis of the power spectral density of the track irregularities described in accordance with ORE B176 [33] and the specifications included in the UIC 518 Leaflet [31] regarding the track geometrical quality described by the quality levels QN1 and QN2.

Against each wheelset, the track lateral irregularities are described by the function $\zeta_{j,,(j+1)}\left(x_{j,(j+1)}\right)$, dependent on the distance along the track, as such

$$
\begin{aligned}
& \zeta_{j, j+1}\left(x_{j,(j+1)}\right)=0, \text { for } x_{j,(j+1)} \leq 0 ; \zeta_{j, j+1}\left(x_{j, j+1}\right)=\zeta\left(x_{j,(j+1)}\right) \text {, for } \\
& x_{j,(j+1)}>0, \\
& \text { with, } x_{1}=x ; \quad x_{2}=x-2 a_{b}, \text { for } i=1 ; \quad x_{3}=x-2 a_{c} ; \\
& x_{4}=x-2 a_{b}-2 a_{c}, \text { for } i=2 .
\end{aligned}
$$




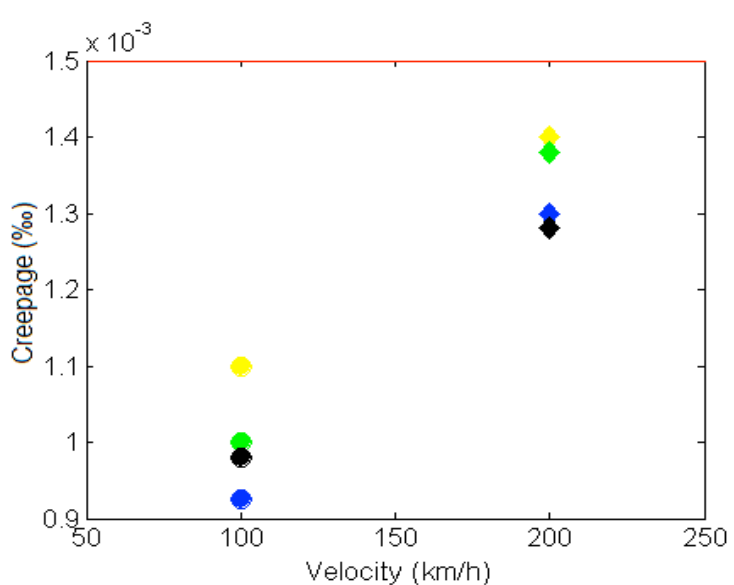

Fig. 13. Wheelset creepage for QN1: - , 1 wheelset; - 2, wheelset; - , 3 wheelset; -, 4 wheelset.

To determine the applicability limits of the linear model, the velocities of $100 \mathrm{~km} / \mathrm{h}$ and $200 \mathrm{~km} / \mathrm{h}$ will be taken into account, along with both quality levels for the track, QN1 and QN2 [31], for which the creepage will be calculated in the wheel-rail contact points for all four wheelsets of the vehicle (see Fig. 13 and Fig. 14). The prerequisite regarding the value of the creepage $(v<0.0015)$, for which the vehicle linear model is valid, is only met during running on a QN1
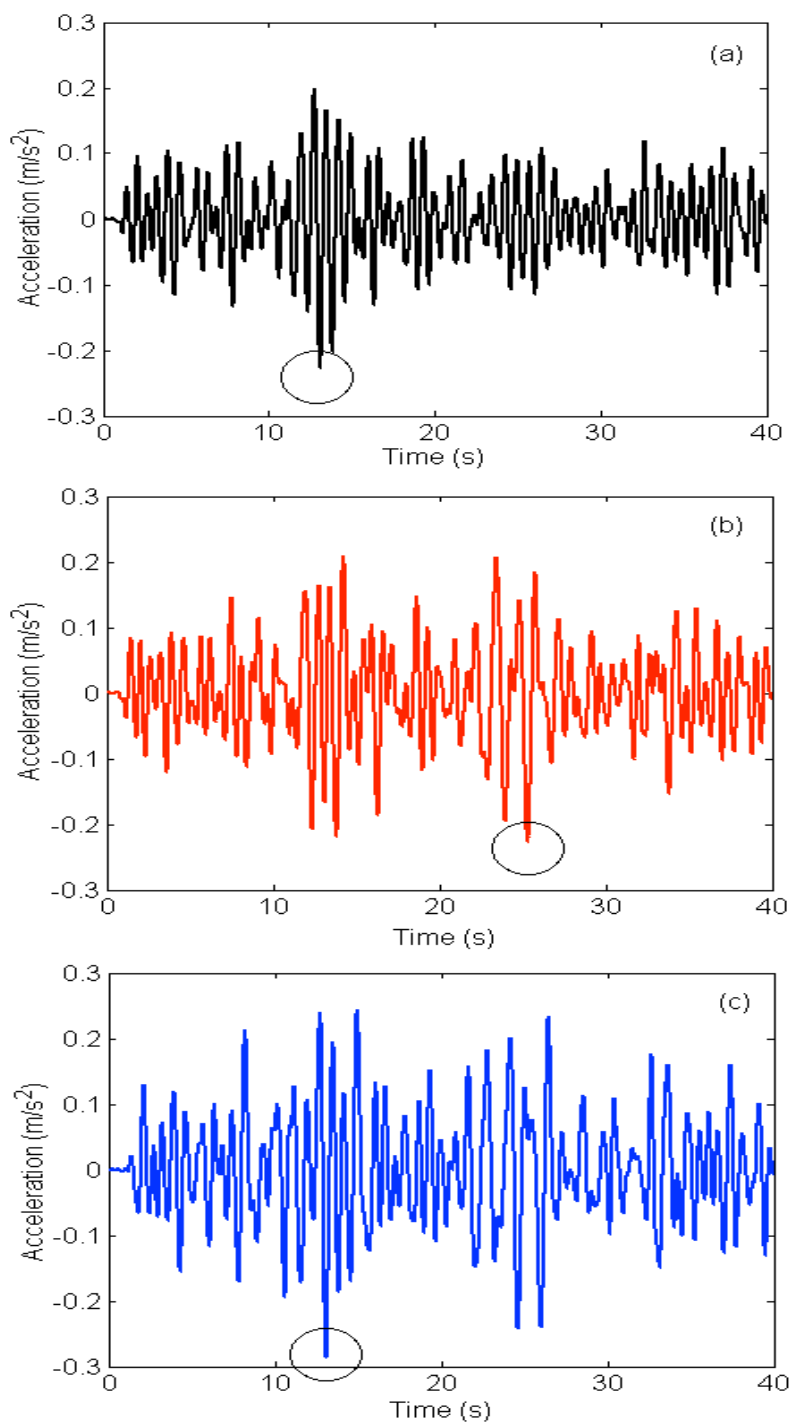

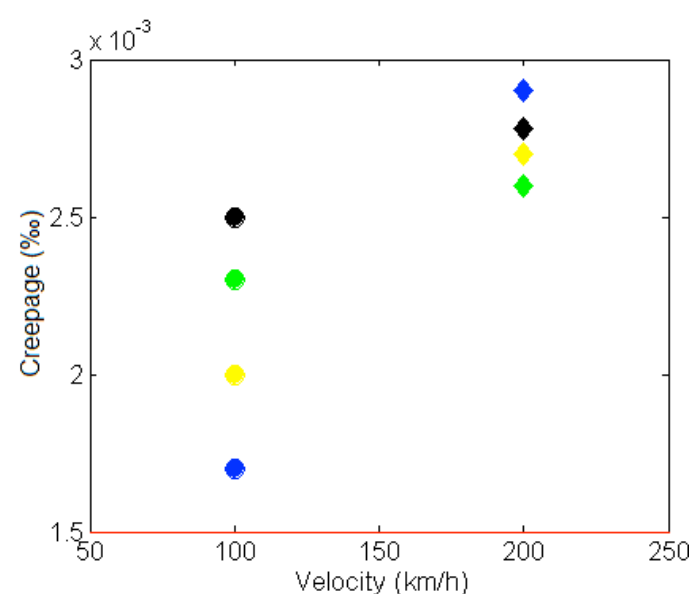

Fig. 14. Wheelset creepage for QN2: , 1 wheelset; - 2, wheelset; - , 3 wheelset; - 4 wheelset.

quality track. For this case, the carbody lateral accelerations calculated in the three reference points via the linear model and the non-linear model will be compared (see Fig. 15 and Fig. 16). The comparison units are represented by the maximum values (the encircled peaks) and the root mean square deviation of the lateral acceleration, as seen in Table 6. It has to underline that no flange contact has been signalised in numerical simulation results.
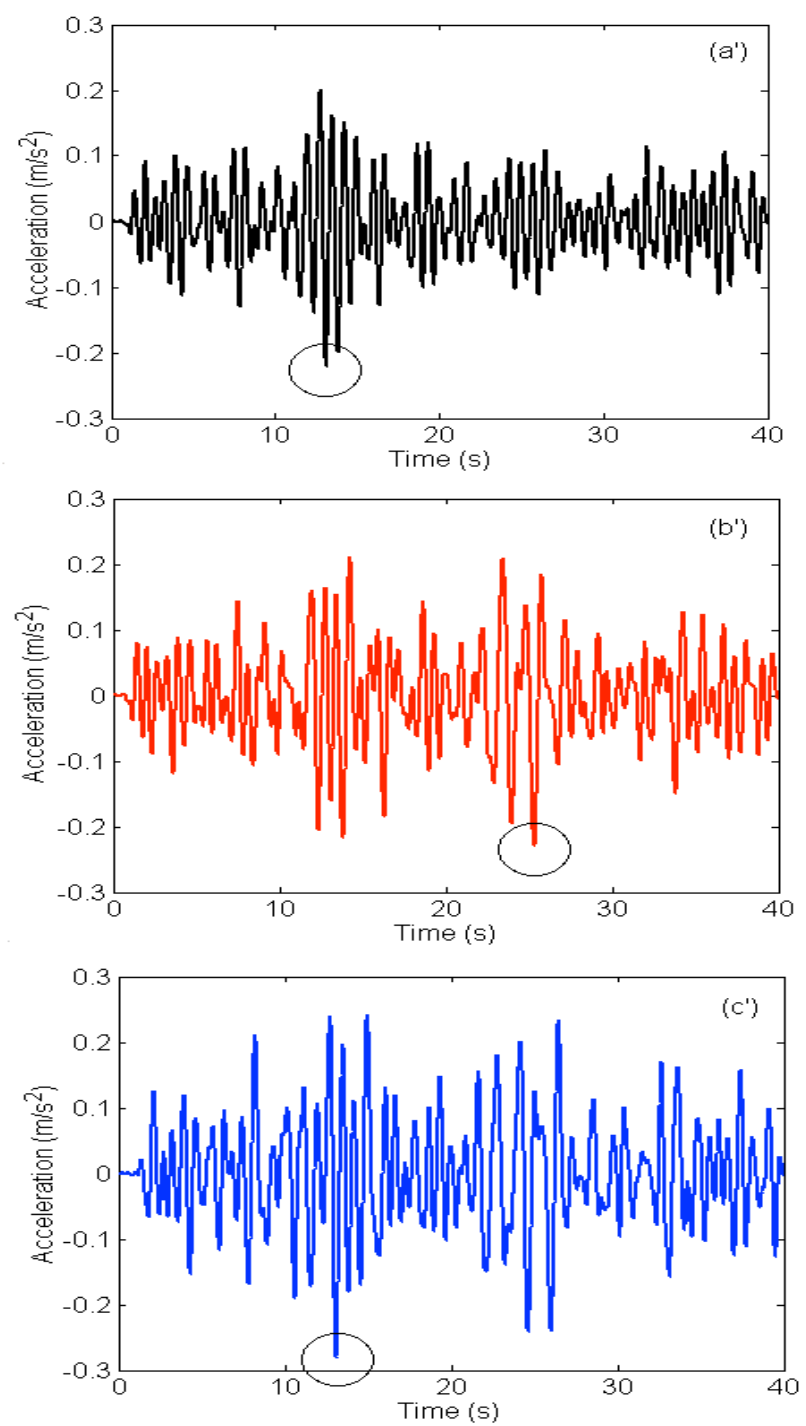

Fig. 15. Carbody lateral acceleration during running at $100 \mathrm{~km} / \mathrm{h}$ velocity on a QN1 quality track: linear model - (a) at the carbody centre; (b) above the front bogie; (c) above the rear bogie; non-linear model - (a') at the carbody centre; (b') above the front bogie; (c') above the rear bogie. 

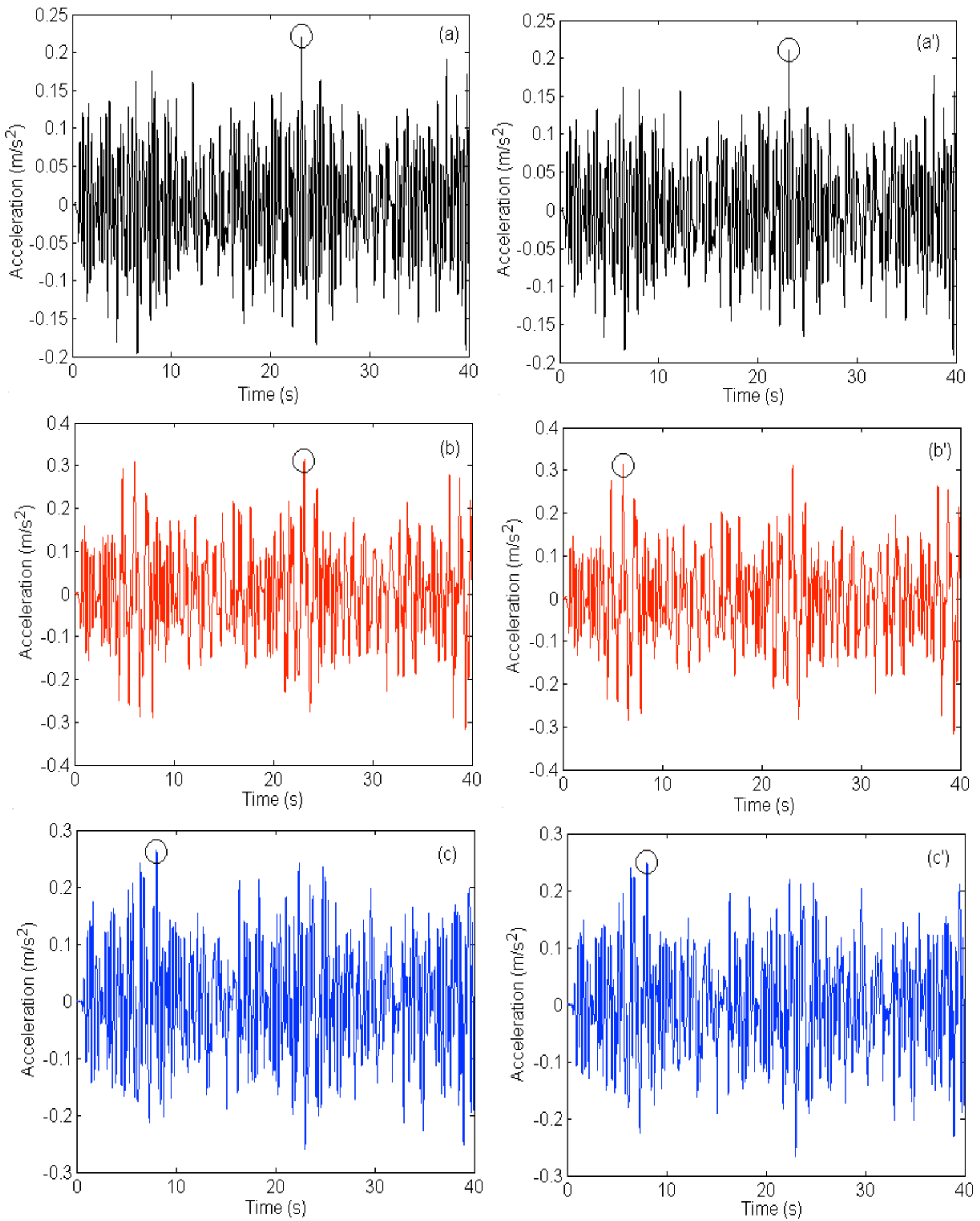

Fig. 16. Carbody lateral acceleration during running at $200 \mathrm{~km} / \mathrm{h}$ velocity on a QN1 quality track: linear model - (a) at the carbody centre; (b) above the front bogie; (c) above the rear bogie; non-linear model - (a') at the carbody centre; (b') above the front bogie; (c') above the rear bogie.

When examining the results for the velocity of $100 \mathrm{~km} / \mathrm{h}$, the differences between the maximum accelerations calculated on the basis of the two models can be shown to fall within the limits $0.91 \% \ldots 2.72 \%$. The root mean square deviation of the acceleration for the linear model is at least $2.07 \%$ higher than the same deviation for the acceleration in the non-linear model of the vehicle. The differences increase along with the velocity; they will be found in the interval
$2.56 \% \ldots 4.20 \%$ for the maximum acceleration at $200 \mathrm{~km} / \mathrm{h}$ velocity and $2.56 \% \quad \ldots 5.13 \%$ for the root mean square deviation of the acceleration.

Finally, the carbody critical point will be above the rear bogie for both models, at the $100 \mathrm{~km} / \mathrm{h}$ velocity. Should velocity goes up to $200 \mathrm{~km} / \mathrm{h}$, the critical point will shift to the front bogie. 
Table 6. The values of the carbody lateral accelerations during running on a QN1 quality track

\begin{tabular}{|c|c|c|c|c|c|c|c|}
\hline \multirow{2}{*}{$\begin{array}{l}\text { Velocity } \\
(\mathrm{km} / \mathrm{h})\end{array}$} & \multirow{2}{*}{$\begin{array}{l}\text { Acceleration } \\
\left(\mathrm{m} / \mathrm{s}^{2}\right)\end{array}$} & \multicolumn{3}{|c|}{ Linear model } & \multicolumn{3}{|c|}{ Non-linear model } \\
\hline & & $\begin{array}{l}\text { at the } \\
\text { carbody } \\
\text { centre }\end{array}$ & $\begin{array}{l}\text { above the } \\
\text { front bogie }\end{array}$ & $\begin{array}{l}\text { above the } \\
\text { rear bogie }\end{array}$ & $\begin{array}{c}\text { at the } \\
\text { carbody } \\
\text { centre }\end{array}$ & $\begin{array}{c}\text { above the } \\
\text { front bogie }\end{array}$ & $\begin{array}{l}\text { above the } \\
\text { rear bogie }\end{array}$ \\
\hline & $\begin{array}{l}\text { Maximum } \\
\text { value }\end{array}$ & 0.2266 & 0.2276 & 0.2868 & 0.2206 & 0.2297 & 0.2811 \\
\hline 100 & $\begin{array}{l}\text { Root mean } \\
\text { square } \\
\text { deviation }\end{array}$ & 0.0703 & 0.0737 & 0.0884 & 0.0690 & 0.0722 & 0.0879 \\
\hline & $\begin{array}{l}\text { Maximum } \\
\text { value }\end{array}$ & 0.2204 & 0.3164 & 0.2643 & 0.2115 & 0.3174 & 0.2555 \\
\hline 200 & $\begin{array}{l}\text { Root mean } \\
\text { square } \\
\text { deviation }\end{array}$ & 0.0655 & 0.0958 & 0.0873 & 0.0623 & 0.0934 & 0.0832 \\
\hline
\end{tabular}

\section{Conclusions}

The paper features a set of analyses based on which there have been determined the limits where the linear models can be used for the study of the lateral dynamic behaviour during running on a track with lateral irregularities, depending on the velocity regime. It has been demonstrated that these limits do not cover a domain where all the specific situations in the exploitation of the railway vehicles be included; the reference here is made to the least unfavourable conditions running at high velocity on a track with lateral irregularities, whose amplitude can have the maximum value admitted.

Within the limits of the applicability domain of the linear model, the analyses made via the comparison of the accelerations at the carbody level derived from the linear model with the non-linear ones have proved close results by using the two models. Significant differences, which can reach up to $16 \%$, will be visible in conditions of running at a high velocity on a track with lateral isolated defects. It is worthwhile noticing that the differences between the results of the two models occur at the applicability limit of the linear model (for close creepage or equal with the limit value 0.0015).

When introducing the concept of critical point as that carbody reference point where the level of vibrations is the highest, it was demonstrated that its position was not affected by the model in use but by the running conditions, namely the excitation frequency or the velocity.

\section{Acknowledgments}

This work has been funded by University Politehnica of Bucharest, through the "Excellence Research Grants" Program, UPB - GEX - 2016. Research project title: Research on developing mechanical and numerical models for the virtual evaluation of the dynamic performances in the railway vehicles (in Romanian). Contract number: 48/26.09.2016

This is an Open Access article distributed under the terms of the Creative Commons Attribution Licence

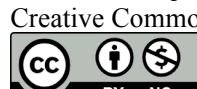

\section{References}

1. J. Evans, M. Berg, Challenges in simulation of rail vehicle dynamics, Vehicle System Dynamics, 47, pp. 1023-1048 (2009).

2. G. Schupp, Simulation of railway vehicles: Necessities and applications, Mechanics Based Design of Structures and Machines, 31 (3), pp. 297-314 (2003).

3. T. Mazilu, M. Dumitriu, C. Tudorache, Instability of an oscillator moving along a Timoshenko beam on viscoelastic foundation, Nonlinear Dynamics, 67 (2), pp. 1273-1293 (2012).

4. T. Mazilu, M. Dumitriu, C. Tudorache, On the dynamic effect between a moving mass and an infinite one-dimensional elastic structure at the stability limit, Journal of Sound and Vibration, 330 (15), pp. 3729-3743 (2011).

5. T. Mazilu, Instability of a train of oscillators moving along a beam on a viscoelastic foundation, Journal of Sound and Vibration, 332 (19), pp. 4597-4619 (2013).

6. Y.C. Cheng, C.T. Hsu, Hunting stability and derailment analysis of a car model of a railway vehicle system, Proceedings of the Institution of Mechanical Engineers, Part F: Journal of Rail and Rapid Transit, 226 (2), pp. 187 - 202 (2012).

7. B. Suarez, J.M. Mera, M.L. Martinez, J.A. Chover, Assessment of the influence of the elastic properties of rail vehicle suspensions on safety, ride quality and track fatigue, Vehicle System Dynamics, 51 (2), pp. 280-300 (2013).

8. Y.Q. Sun, C. Cole, M. Spiryagin, Study on track dynamic forces due to rail short-wavelength dip defects using rail vehicle-track dynamics simulations, Journal of Mechanical Science and Technology, 27 (3), pp. 629-640 (2013).

9. Y. He, J. McPhee, Optimization of the lateral stability of rail vehicles, Vehicle System Dynamics, 38 (5), pp. 361-390 (2002).

10. L. Mazzola, S. Alfi, S. Bruni, A method to optimize stability and wheel wear in railway bogies, International Journal of Railway, $\mathbf{3}$ (3), pp. 95-105 (2010).

11. S. Bruni, J. Vinolas, M. Berg, O. Polach, S. Stichel, Modelling of suspension components in a rail vehicle dynamics context. Vehicle System Dynamics, 49 (7), pp. 1021-1072 (2011).

12. C. Funfschilling, Y. Bezin, M. Sebès, DynoTRAIN: Introduction of simulation in the certification process of railway vehicles, Transport Research Arena, Paris, (2014).

13. C. Funfschilling, G. Perrin, S. Kraft S, Propagation of variability in railway dynamic simulations: Application to virtual homologation, Vehicle System Dynamics, 50, pp. 245-261 (2012).

14. N. Burgelman, M. Sh. Sichani, R. Enblom, M. Berg, R. Dollevoet, Influence of wheel-rail contact modelling on vehicle dynamic simulation, Vehicle System Dynamics, 53 (8), pp. 1190-1203 (2015).

15. O. Polach, On non-linear methods of bogie stability assessment using computer simulations, Proceedings of the Institution of Mechanical Engineers, Part F: Journal of Rail and Rapid Transit, 220, pp. 13-27 (2006).

16. Y.C. Cheng, S.Y. Leeb, H.H. Chen, Modeling and nonlinear hunting stability analysis of high-speed railway vehicle moving on 
curved track, Journal Sound and Vibration, 324, pp. 139-160 (2009).

17. T. Mazilu, M. Dumitriu, On the instability of the railway vehicles, Mechanical Journal Fiability and Durability, 2 (8), pp. 1-6 (2011).

18. Z.Y. Shen, J.K. Hedrick, J.A. Elkins, A comparison of alternative creep force models for rail vehicle dynamic analysis, Proceedings of the 8th IAVSD Symposium, Cambridge, MA, pp. 591-605 (1983).

19. O. Polach, A fast wheel-rail forces calculation computer code, Vehicle System Dynamics, 33, pp. 728-739 (1999).

20. M. Dumitriu, Influence of the suspension parameters upon the hunting movement stability of the railway vehicles, Mechanical Journal Fiability and Durability, 1, pp. 129-136 (2014).

21. M. Dumitriu, Influence of the longitudinal and lateral suspension damping on the vibration behaviour in the railway vehicles, Archive of Mechanical Engineering, 62 (1), pp. 115-140 (2015).

22. C.E. Bell, D. Horak, J.K. Hedrick, Stability and curving mechanics of rail vehicles, Transaction of the ASME Journal of Dynamic, Systems, Measurement and Control, 103, pp.181-190 (1981).

23. J.J. Kalker, On the rolling contact of two elastic bodies in the presence of dry friction, Ph.D. Thesis, Delft (1967).

24. M. Dumitriu, Numerical analysis of the influence of lateral suspension parameters on the ride quality of railway vehicles, Journal of Theoretical and Applied Mechanics, 54 (4), pp. 12311243 (2016).
25. M. Dumitriu, C. Crăciun, Evaluation of stability in railway vehicles on basis of bogie lateral acceleration, Applied Mechanics and Materials, 809-810, pp 1031-1036 (2015).

26. M. Dumitriu, I. Sebeşan, Ride quality of railway vehicles, (in Romanian), Matrix Rom, Bucharest (2016).

27. S.Y. Lee, Y.C. Cheng, Hunting stability analysis of high-speed railway vehicle trucks on tangent tracks, Journal of Sound and Vibration, 282, pp. 881-898 (2005).

28. A.H. Wickens, Fundamentals of rail vehicles dynamics: Guidance and stability, Taylor \& Francis e-Library (2005).

29. I. Sebeşan, Dynamic of the railway vehicles, (in Romanian) Matrix Rom, Bucharest (2011).

30. M. Dumitriu, Modelling the geometric contact between wheels and the rails of a track with horizontal irregularity, Mechanical Journal Fiability and Durability, 1, pp. 116 - 122 (2013).

31. UIC 518 Leaflet, Testing and approval of railway vehicles from the point of view of their dynamic behaviour - Safety -Track Fatigue - Ride Quality (2009).

32. M. Dumitriu, Numerical synthesis of the track alignment and applications. Part I: The synthesis method, Transport Problems, 11 (1), pp. 19-28 (2016).

33. ORE B 176, Bogies with steered or steering wheelsets, Report No. 1: Specifications and preliminary studies, Vol. 2, Specification for a bogie with improved curving characteristics (1989).

Annex 1. The parameters of the vehicle model.

\begin{tabular}{|c|l|l|l|}
\hline$m_{c}$ & Carbody mass & $2 c_{z c}$ & Vertical damping of the secondary suspension $^{*}$ \\
\hline$m_{b}$ & Mass of suspended bogie & $c_{y c}$ & Lateral damping of the secondary suspension \\
\hline$m_{w}$ & Wheelset mass & $2 c_{x c}$ & $\begin{array}{l}\text { Longitudinal damping of the secondary } \\
\text { suspension }\end{array}$ \\
\hline$J_{x c} J_{z c}$ & The inertia moments of the carbody & $2 k_{z c}$ & Vertical rigidity of the secondary suspension \\
\hline$J_{x b}$ & The inertia moments of the bogie chassis & $2 k_{y c}$ & Lateral rigidity of the secondary suspension $^{*}$ \\
\hline$J_{z b}$ & The inertia moments of the wheelset & $2 k_{x c}$ & Longitudinal rigidity of the secondary suspension $^{*}$ \\
\hline$J_{z w}$ & The vehicle wheelbase & $k_{\mathrm{jc}}$ & Torsional stiffness of the secondary suspension $^{*}$ \\
\hline $2 a_{c}$ & The primary suspension \\
\hline $2 a_{b}$ & The bogie wheelbase & $2 c_{z b}$ & Vertical damping of the primas $^{* *}$ \\
\hline $2 b_{c}$ & The lateral base of the secondary suspension & $2 c_{y b}$ & Lateral damping of the primary suspension $^{* *}$ \\
\hline $2 b_{b}$ & The lateral base of the primary suspension & $2 c_{x b}$ & Longitudinal damping of the primary suspension $^{* *}$ \\
\hline$h_{c}$ & $\begin{array}{l}\text { Distance of the carbody mass centre compared to } \\
\text { the plan of secondary suspension }\end{array}$ & $2 k_{z b}$ & Vertical rigidity of the primary suspension $^{* *}$ \\
\hline$h_{b 1}$ & $\begin{array}{l}\text { Distance of the bogie mass centre compared to } \\
\text { the wheelset axis }\end{array}$ & $2 k_{y b}$ & Lateral rigidity of the primary suspension $^{* *}$ \\
\hline$h_{b 2}$ & $\begin{array}{l}\text { Distance of the bogie mass centre compared to } \\
\text { the plan of secondary suspension }\end{array}$ & $2 k_{x b}$ & Longitudinal rigidity of the primary suspension $^{* *}$ \\
\hline$r_{w}$ & $\begin{array}{l}\text { The radius of the rolling circle when wheelset } \\
\text { occupies the median position on the track }\end{array}$ & $k_{y r}$ & The rail lateral stiffness $^{*}$ \\
\hline
\end{tabular}

* per bogie; ${ }^{* *}$ per axle. 